\title{
Serine 574 phosphorylation alters transcriptional programming of FOXO3 by selectively enhancing apoptotic gene expression
}

\author{
Z Li ${ }^{1}$, J Zhao ${ }^{1}$, I Tikhanovich ${ }^{1}$, S Kuravi ${ }^{1}$, J Helzberg ${ }^{1}$, K Dorko $^{2}$, B Roberts ${ }^{3}$, S Kumer ${ }^{4}$ and SA Weinman ${ }^{\star, 1}$
}

Forkhead box 03 (FOXO3) is a multispecific transcription factor that is responsible for multiple and conflicting transcriptional programs such as cell survival and apoptosis. The protein is heavily post-translationally modified and there is considerable evidence that post-transcriptional modifications (PTMs) regulate protein stability and nuclear-cytosolic translocation. Much less is known about how FOXO3 PTMs determine the specificity of its transcriptional program. In this study we demonstrate that exposure of hepatocytes to ethanol or exposure of macrophages to lipopolysaccharide (LPS) induces the c-Jun N-terminal kinase (JNK)-dependent phosphorylation of FOXO3 at serine-574. Chromatin immunoprecipitation (ChIP), mRNA and protein measurements demonstrate that p-574-FOXO3 selectively binds to promoters of pro-apoptotic genes but not to other well-described FOXO3 targets. Both unphosphorylated and p-574-FOXO3 bound to the B-cell lymphoma 2 (Bcl-2) promoter, but the unphosphorylated form was a transcriptional activator, whereas p-574-FOXO3 was a transcriptional repressor. The combination of increased TRAIL (TNF-related apoptosis-inducing ligand) and decreased Bcl-2 was both necessary and sufficient to induce apoptosis. LPS treatment of a human monocyte cell line (THP-1) induced FOXO3 S-574 phosphorylation and apoptosis. LPS-induced apoptosis was prevented by knockdown of FOXO3. It was restored by overexpressing wild-type FOXO3 but not by overexpressing a nonphosphorylatable S-574A FOX03. Expression of an S-574D phosphomimetic form of FOXO3 induced apoptosis even in the absence of LPS. A similar result was obtained with mouse peritoneal macrophages where LPS treatment increased TRAIL, decreased Bcl-2 and induced apoptosis in wild-type but not $\mathrm{FOXO}^{-/}$cells. This work thus demonstrates that S-574 phosphorylation generates a specifically apoptotic form of FOXO3 with decreased transcriptional activity for other well-described FOXO3 functions.

Cell Death and Differentiation (2016) 23, 583-595; doi:10.1038/cdd.2015.125; published online 16 October 2015

Forkhead box $\mathrm{O} 3$ (FOXO3) is a multispecific transcription factor that serves as a longevity factor ${ }^{1,2}$ and tumor suppressor and is critically involved in multiple seemingly independent biological process including cell-cycle arrest, ${ }^{3}$ DNA repair, ${ }^{4}$ antioxidant and stress responses, ${ }^{5}$ apoptosis, ${ }^{6}$ autophagy, glucose metabolism and aging. ${ }^{7}$ Its many transcriptional programs are frequently in opposition to each other as it induces apoptosis, yet it is also critical for cell survival and longevity. Although there is considerable information regarding the mechanisms that regulate the nuclear/cytosolic distribution and protein stability of FOXO3, the control mechanisms that regulate transcriptional specificity are poorly understood.

FOXO3 function is tightly regulated by multiple posttranslational modifications (PTMs) including phosphorylation, acetylation, ubiquitination and arginine and lysine methylation. Specific PTMs regulate the partitioning of $\mathrm{FOXO} 3$ between the cytosol and the nucleus ${ }^{8-15}$ and its stability and degradation, ${ }^{16}$ but the links between specific PTMs and FOXO3 transcriptional specificity are less well understood.
Brunet et al..$^{17}$ showed that acetylation favors expression of pro-apoptotic as opposed to antioxidant genes, but the sites responsible for this are unclear. ${ }^{18}$ Other studies have suggested that that deacetylation reduces apoptotic transcription primarily by enhancing $\mathrm{FOXO} 3$ ubiquitination thus reducing gene expression through $\mathrm{FOXO} 3$ degradation. ${ }^{19,20}$ Other than acetylation, specific PTMs that control the $\mathrm{FOXO} 3$ transcriptional program have not been identified, and effects such as context-dependent alterations in DNA and histone structure ${ }^{21}$ or binding of transcriptional repressors, such as NFIL $3{ }^{22}$ are thought to play the major role in transcriptional specificity tuning.

In our previous work we observed that alcohol treatment of hepatocytes generated specific PTM patterns of FOXO3, particularly those resulting from phosphorylation and arginine demethylation. ${ }^{23}$ In the present study, we sought to determine whether these modified forms of $\mathrm{FOXO} 3$ cause preferential target gene transcription. We observed that ethanol (EtOH) induces a c-Jun N-terminal kinase (JNK)-dependent phosphorylation of FOXO3 at serine-574 (S-574) and this

\footnotetext{
${ }^{1}$ Department of Internal Medicine, University of Kansas Medical Center, Kansas City, KS 66160, USA; ${ }^{2}$ Department of Pharmacology, Toxicology \& Therapeutics, University of Kansas Medical Center, Kansas City, KS 66160, USA; ${ }^{3}$ Liver Center, University of Kansas Medical Center, Kansas City, KS 66160, USA and ${ }^{4}$ Department of Surgery, University of Kansas Medical Center, Kansas City, KS 66160, USA

${ }^{*}$ Corresponding author: SA Weinman, Department of Internal Medicine, University of Kansas Medical Center, Mailstop 1018, Kansas City, KS 66160, USA. Tel: +1 913945 6945; Fax +1 913588 7501; E-mail: sweinman@ kumc.edu

Abbreviations: FOXO3, forkhead box O3; PTM, post-transcriptional modification; LPS, lipopolysaccharide; ChIP, chromatin immunoprecipitation; TRAIL, TNF-related apoptosis-inducing ligand; Bcl-2, B-cell lymphoma 2; Prxlll, peroxiredoxin III; SOD2, superoxide dismutase 2; Bim, B-cell lymphoma 2 interacting mediator of cell death; TUNEL, terminal deoxynucleotidyl transferase dUTP nick end labeling; LDH, lactate dehydrogenase; JNK, c-Jun N-terminal kinase; PUMA, p53 upregulated modulator of apoptosis; Noxa, phorbol-12-myristate-13-acetate-induced protein 1; ADH, alcohol dehydrogenase; HCV, hepatitis C virus Received 10.3.15; revised 17.8.15; accepted 20.8.15; Edited by N Chandel; published online 16.10 .15
} 
altered the transcriptional specificity of FOXO3, converting it from an antioxidant to an apoptosis-inducing transcription factor. In addition to selectively activating transcription of previously reported pro-apoptotic genes, such as TRAIL (TNF-related apoptosis-inducing ligand), p-574-FOXO3 was a transcriptional repressor of the anti-apoptotic protein B-cell lymphoma 2 (Bcl-2). The combination of an increase in TRAIL and a decrease in Bcl-2 were both sufficient and necessary for apoptosis induction. These results demonstrate that in addition to regulating stability, nuclear translocation and transcriptional efficiency, specific FOXO3 PTMs can alter its transcriptional program, converting it into a potent apoptosis inducer.

\section{Results}

EtOH reprograms $\mathrm{FOXO3}$ by selectively enhancing its pro-apoptotic effects. In order to assess the effects of alcohol on FOXO3 we treated Huh7.5 hepatoma cells with or without $50 \mathrm{mM}$ EtOH for $48 \mathrm{~h}$ and performed ChIP studies with an endogenous FOXO3 antibody (Figure 1a) or with an anti-HA antibody after overexpression of HA-FOXO3 (Figure 1b). A range of promoter targets were examined to represent the different transcriptional programs of FOXO3. $\mathrm{EtOH}$ treatment resulted in increased promoter binding to the pro-apoptotic genes, Bim (B-cell lymphoma 2 interacting mediator of cell death) and TRAIL, but had only minor and nonsignificant effects on other target genes (Figures 1a and b). This effect was present at the mRNA and protein levels as well (Figures 1c and d). HA-FOXO3 overexpression itself increased superoxide dismutase 2 (SOD2) and peroxiredoxin III (PrxIII) mRNA but had no effect on Bim and TRAIL. Subsequent EtOH treatment, however, significantly increased both Bim and TRAIL mRNA (Figure 1c). FOXO3 overexpression increased SOD2 and FOXO1 protein levels and EtOH treatment subsequently increased TRAIL (Figure 1d). The lack of precise agreement between mRNA and protein levels for Bim and Prxlll suggests that these proteins may be controlled by nontranscriptional mechanisms as well.

To determine whether these pro-apoptotic gene expression changes cause cell death, FOXO3-overexpressing cells were treated with $50 \mathrm{mM} \mathrm{EtOH}$ for $48 \mathrm{~h}$ and assessed by TUNEL (terminal deoxynucleotidyl transferase dUTP nick end labeling) assay, $\mathrm{LDH}$ release and caspase activation. EtOH treatment of untransfected Huh7.5 cells did not cause cell death, but after $\mathrm{FOXO} 3$ overexpression, $\mathrm{EtOH}$ caused a significant increase in TUNEL positivity, LDH release and caspase 3/7 activity (Figures 1e-g). DR4 and DR5, the TRAIL receptor antagonists, ${ }^{24}$ significantly blocked $\mathrm{FOXO} / \mathrm{EtOH}$-induced increase of $\mathrm{LDH}$ release and caspase $3 / 7$ activity (Figures $1 f$ and $\mathrm{g}$ ), demonstrating that $\mathrm{FOXO} / \mathrm{EtOH}$-induced cell death was TRAIL dependent. These data indicate that EtOH reprograms FOXO3, enhancing its activation of pro-apoptotic target genes that contribute to TRAIL-dependent apoptosis.

\section{EtOH causes FOXO3 S-574 phosphorylation. We previously observed that hepatitis $\mathrm{C}$ virus (HCV) infection induced JNK-dependent phosphorylation of FOXO3 at S-574. ${ }^{23}$ The specificity and functional consequences of this phosphorylation are unknown. We generated a specific}

antibody to phospho-S-574-FOXO3 (p-574-FOXO3) and used it to examine the effects of $\mathrm{EtOH}$ on this FOXO3 modification. The antibody showed high specificity for p-574-FOXO3 (Supplementary Figure S1). Huh7.5 cells and primary human hepatocytes showed undetectable levels of p-574-FOXO3 in the absence of $\mathrm{EtOH}$ treatment, but exposure to $\mathrm{EtOH}$ for $12 \mathrm{~h}$ resulted in robust FOXO3 S-574 phosphorylation in both cell types (Figure 2a). S-574 FOXO3 phosphorylation induced by either JNK overexpression or EtOH was JNK dependent as in both cases it was blocked by JNK inhibitor (Figure 2b). Immunofluorescence studies showed that total $\mathrm{FOXO} 3$ was present in both nucleus and cytosol and its distribution was not changed by EtOH (Figure 2c). p-574-FOXO3 was only detectable after EtOH exposure, was primarily nuclear and its formation was blocked by JNK inhibitor (Figures $2 \mathrm{c}$ and $\mathrm{d}$ ). The JNK inhibitor significantly reduced $\mathrm{LDH}$ release from $\mathrm{EtOH}$-treated FOXO3-overexpressing Huh7.5 cells (Figure 2e).

Apoptotic effects of p-574-FOX03. To investigate the functional properties of $\mathrm{p}-574-\mathrm{FOXO3}$, we used the p-574FOXO3 antibody for chromatin immunoprecipitation (ChIP) analysis. The results demonstrated that p-574-FOXO3 bound primarily to apoptotic gene targets Bim and TRAIL, but not to antioxidant gene targets SOD2 and PrxIII (Figure 3a). We next examined the phosphorylation-deficient mutant, FOXO3574A to determine whether FOXO3/EtOH apoptosis required this modification. Unlike the situation for WT-FOXO3, EtOH treatment of FOXO3 S-574A-expressing cells failed to increase promoter binding to Bim and TRAIL (Figure 3b) and also failed to increase Bim and TRAIL mRNA (Figure 3c). To further confirm the role of S-574 phosphorylation in apoptosis we used a phosphomimetic form, FOXO3 S-574D. The WT-FOXO3 induced apoptosis only after exposure to $\mathrm{EtOH}, \mathrm{FOXO} 3 \mathrm{~S}-574 \mathrm{~A}$ failed to induce apoptosis with or without EtOH and FOXO3 S-574D induced apoptosis irrespective of whether or not EtOH was present (Figures 3df). Alcohol thus induces formation of a novel pro-apoptotic, phosphorylated form of FOXO3 in Huh7.5 cells.

FOXO3/EtOH is a transcriptional repressor of $\mathrm{Bcl}-2$. Although p-574-FOXO3 is specifically pro-apoptotic, the observed changes in TRAIL and BIM were modest. Furthermore, the EtOH/FOXO3 combination dramatically increased the sensitivity of cells to exogenous TRAIL (Figure 4a). This suggests that mechanisms other than increased TRAIL account for apoptosis induction. We therefore used an apoptosis-related PCR array and identified nine apoptosisrelated gene products that were altered either by FOXO3 or by the combination of $\mathrm{FOXO} 3$ and $\mathrm{EtOH}$ (Table 1). FOXO3 overexpression induced both pro- and anti-apoptotic genes, but in each case, subsequent addition of $\mathrm{EtOH}$ further increased pro-apoptotic genes or decreased anti-apoptotic genes. This effect was particularly striking for Bcl-2 where FOXO3 overexpression induced a 30 -fold increase of $\mathrm{Bcl}-2$ mRNA that was then completely abolished by $\mathrm{EtOH}$.

The Bcl-2 promoter has three potential FHRE motifs. ChIP studies showed that FOXO3 bound strongly to two of these promoter regions and $\mathrm{EtOH}$ treatment increased binding in both cases. In the absence of $\mathrm{EtOH}, \mathrm{FOXO} 3 \mathrm{~S}-574 \mathrm{~A}$ bound to 
a

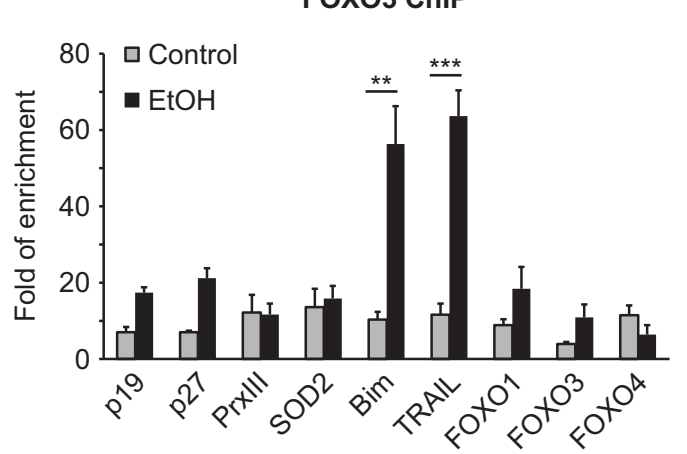

C

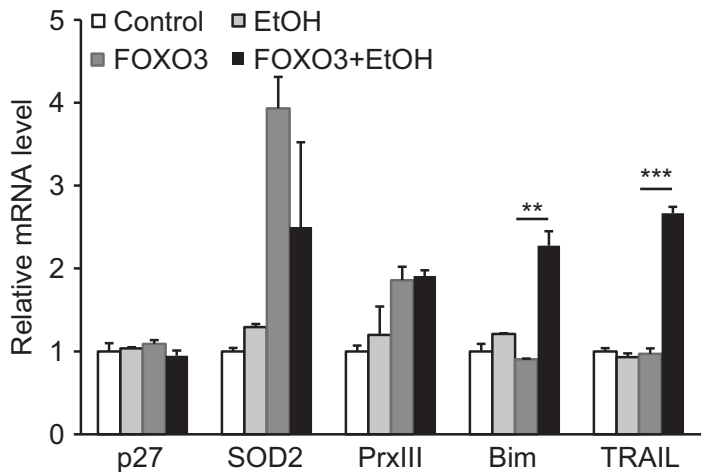

b

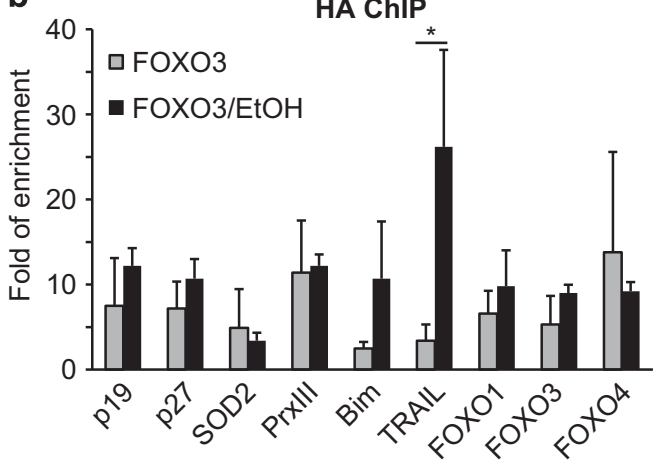

d

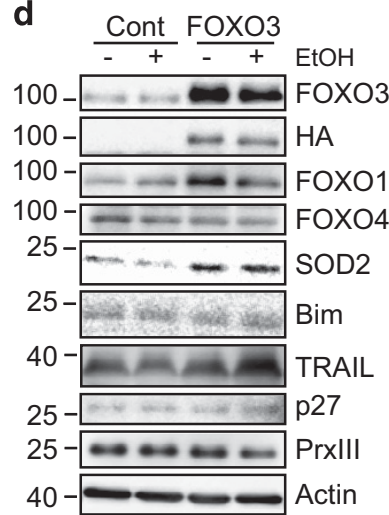

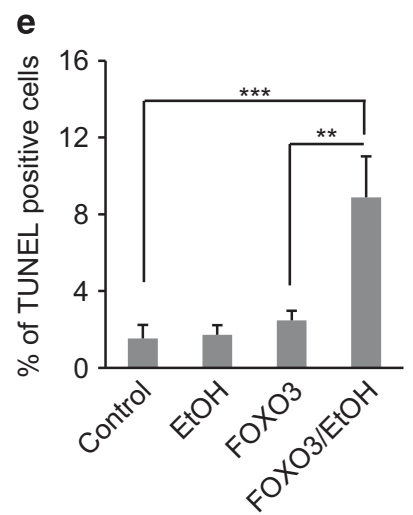
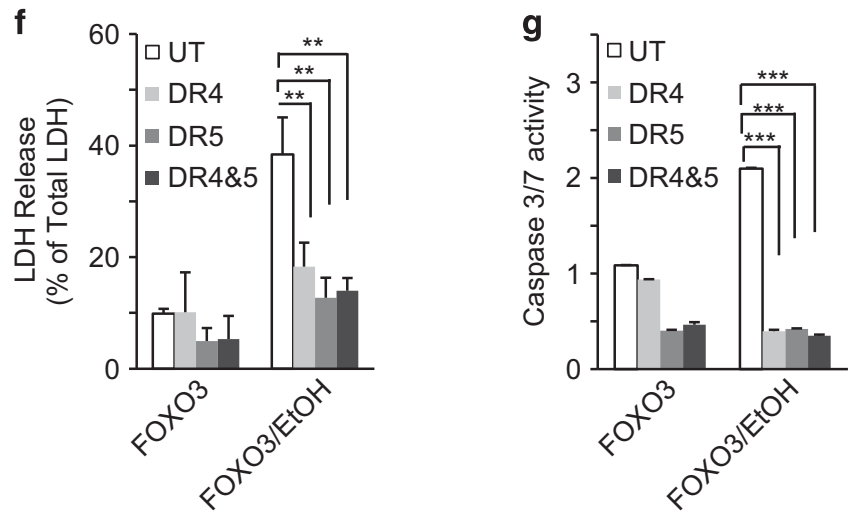

Figure $1 \mathrm{EtOH}$ reprograms FOXO3 selectively enhancing pro-apoptotic effects. (a) Huh7.5 cells were cultured with or without $50 \mathrm{mM}$ EtOH for $48 \mathrm{~h}$. ChIP assay was performed with anti-FOXO3 antibody. Promoters assessed were p19, p27, SOD2 (superoxide dismutase 2), PrxIII (peroxiredoxin III), Bim (Bcl-2-interacting mediator of cell death), TRAIL (TNF-related apoptosis-inducing ligand), FOXO3, FOXO1 and FOXO4. (b) Huh7.5 cells were transfected with HA-tagged FOXO3, treated with or without 50 mM EtOH for additional $48 \mathrm{~h}$, and ChIP assay was performed with anti-HA antibody. (c and d) mRNA (c) and protein (d) measurements of FOXO3 target gene expression were evaluated by real-time RT-PCR and western blot, respectively. (e) Cell death was evaluated by TUNEL assay in cells treated with $50 \mathrm{mM}$ EtOH either with or without FOXO3 transfection. ( $\mathbf{f}$ and $\mathbf{g}$ ) Effects of TRAIL receptor antagonists on FOXO3/EtOH-induced LDH release and caspase activity. FOXO3-transfected cells were treated with or without EtOH in the presence of TRAIL receptor antagonists DR4 $(1 \mu \mathrm{g} / \mathrm{ml})$ or DR5 $(1 \mu \mathrm{g} / \mathrm{ml})$ or the combination $(\mathrm{DR} 4+5)$. Values are mean \pm S.D. of three independent experiments. ${ }^{\star} P<0.05,{ }^{* \star} P<0.01,{ }^{* \star *} P<0.001$, Student's t-test

the $\mathrm{Bcl}-2$ promoter similar to $\mathrm{FOXO3}$, but EtOH had no further effect (Figure 4b). We next performed $\mathrm{Bcl}-2$ promoter luciferase assays to evaluate transcriptional effects. The WT-FOXO3 overexpression induced an $\sim 15$-fold increase of luciferase activity that was reduced by $\mathrm{EtOH}$ treatment. FOXO3 S-574A induced a similar increase of luciferase activity but EtOH had no effect. FOXO3 S-574D showed no transcriptional activity before or after $\mathrm{EtOH}$ treatment (Figure 4c). FOXO3 further induced $\mathrm{Bcl}-2$ mRNA and this effect was suppressed by EtOH. FOXO3 S-574A also increased $\mathrm{Bcl}-2$ mRNA but this was not suppressed by EtOH. FOXO3 S-574D failed to increase Bcl-2 transcription (Figure 4d).

It has previously been reported that $\mathrm{Bcl}-2$ is minimally expressed in hepatocytes under normal conditions. ${ }^{25,26}$ Consistent with these observations, we found low $\mathrm{Bcl}-2$ protein levels in Huh7.5 cells, but FOXO3 overexpression dramatically increased Bcl-2 (Figure 4e, lanes 1-3). Subsequent $\mathrm{EtOH}$ exposure decreased $\mathrm{Bcl}-2$ protein back to 
a

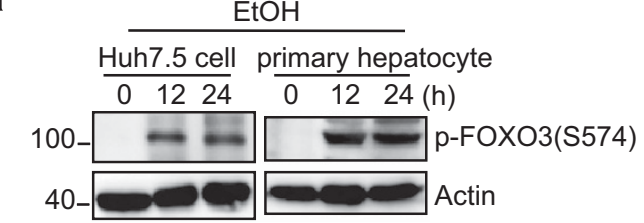

b

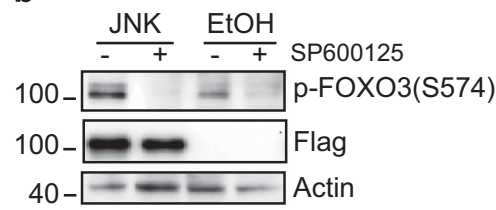

C
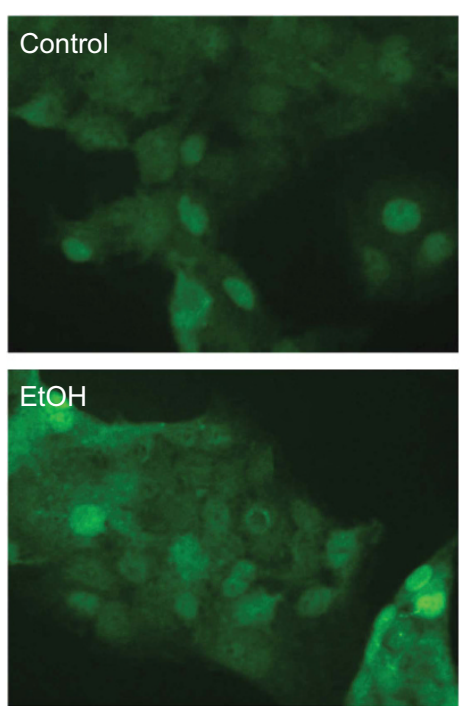

d

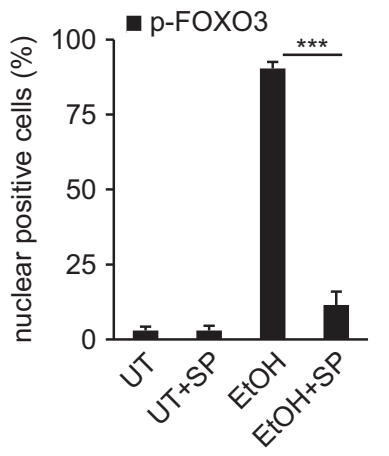

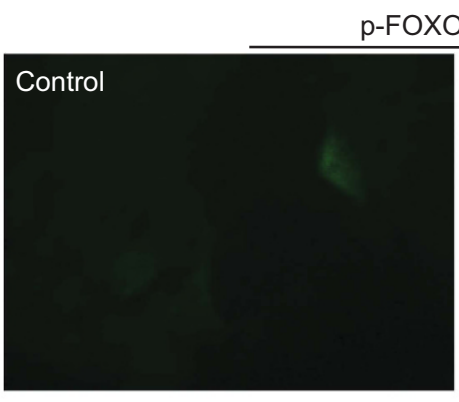

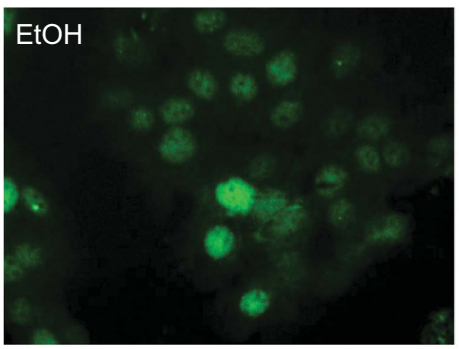

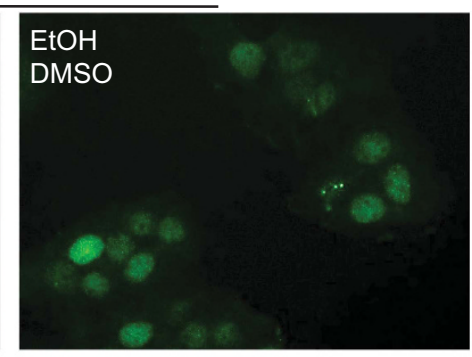

$\mathrm{EtOH}$

SP600125
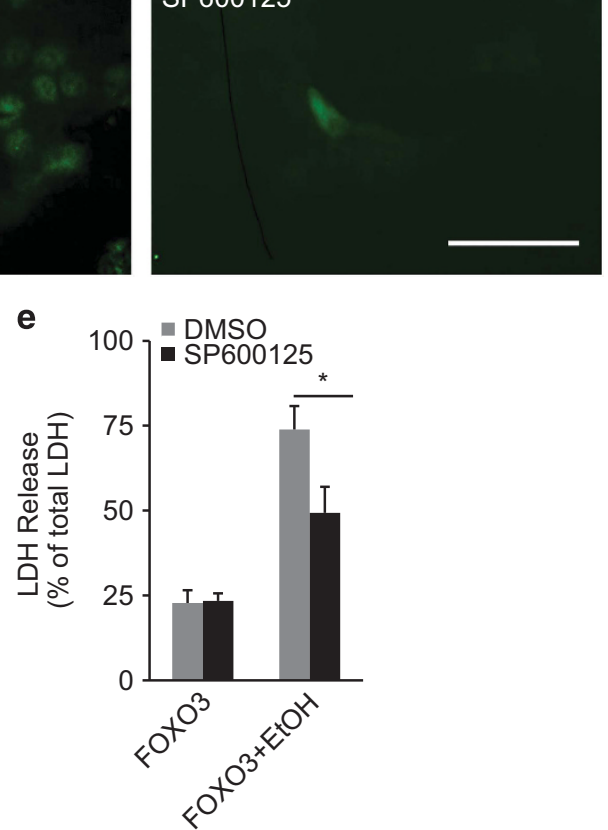

Figure 2 EtOH induces FOXO3 S-574 phosphorylation. (a) Primary human hepatocytes or Huh7.5 cells were incubated with $50 \mathrm{mM}$ EtOH. Whole-cell lysates were blotted for p-574-FOXO3 at indicated times. (b) Huh7.5 cells were transfected with FOXO3 and either co-transfected with JNK1 or treated with $50 \mathrm{mM}$ EtOH. Where indicated, cells were treated with JNK inhibitor SP600125 (100 nM). Cells were harvested $24 \mathrm{~h}$ after treatment and p-574-FOXO3 was analyzed by western blot. (c) Immunofluorescence for total FOXO3 or p-574-FOXO3 in cells treated with EtOH and JNK inhibitor as indicated. Scale bar, $50 \mu \mathrm{m}$. (d) Quantitation of data from imaging studies as in (c). UT, untreated; SP, SP600125. (e) LDH release of FOXO3-transfected cells that were treated with or without $50 \mathrm{mM} \mathrm{EtOH} \mathrm{in} \mathrm{the} \mathrm{presence} \mathrm{or} \mathrm{absence} \mathrm{of} \mathrm{JNK} \mathrm{inhibitor.} \mathrm{Values} \mathrm{are} \mathrm{mean} \pm$ S.D. of three independent experiments. ${ }^{*} P<0.05,{ }^{* \star \star} P<0.001$, Student's $t$-test

the basal level (Figure 4e, lanes 4-6). In contrast, FOXO3 S-574A also increased Bcl-2 protein expression (Figure 4e, lanes 7-9), but EtOH did not antagonize this effect (Figure 4e, lanes 10-11). At the steady state, FOXO3 knockdown was sufficient to lower $\mathrm{Bcl}-2$ protein levels as well (Figure $4 \mathrm{f})$. We further examined liver tissue from wild-type (WT) and $\mathrm{FOXO}^{-/}$mice. $\mathrm{FOXO3}^{-1}$ mice had decreased hepatic $\mathrm{Bcl}-2$ expression as well as lower basal levels of TRAIL (Figure $4 \mathrm{~g}$, lanes $5-8$ ). These data indicate that $\mathrm{FOXO} 3$ is important in the basal expression of $\mathrm{Bcl}-2$ and $\mathrm{EtOH}$-induced S-574 phosphorylation suppresses Bcl-2 expression.
$\mathrm{Bcl}-2$ and TRAIL determine apoptosis in FOXO3/EtOHtreated cells. In order to investigate the relative contribution of TRAIL and $\mathrm{Bcl}-2$ in FOXO3/EtOH-induced apoptosis, we examined Huh7.5 cells that were deficient in TRAIL (TRAIL siRNA) or in which Bcl-2 levels were maintained through $\mathrm{Bcl}-2$ overexpression (Figure $5 \mathrm{a}$ ). Either $\mathrm{Bcl}-2$ overexpression or TRAIL siRNA blocked the ability of $\mathrm{FOXO} / \mathrm{EtOH}$ to induce apoptosis (Figures $5 \mathrm{~b}$ and $\mathrm{c}$ ). This suggests that both high TRAIL and low Bcl-2 are necessary for FOXO3/EtOHinduced cell death. In addition, either decreased $\mathrm{Bcl}-2$ or increased TRAIL alone did not induce apoptosis but the 


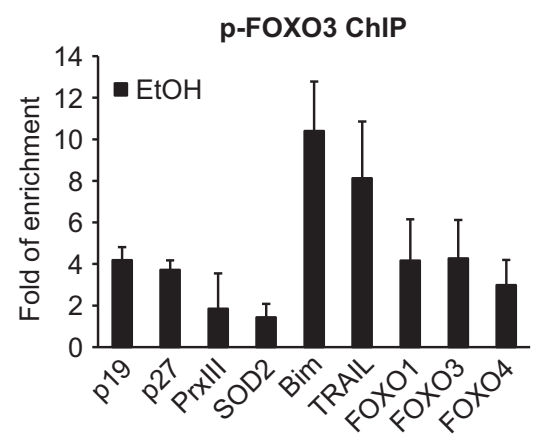

d

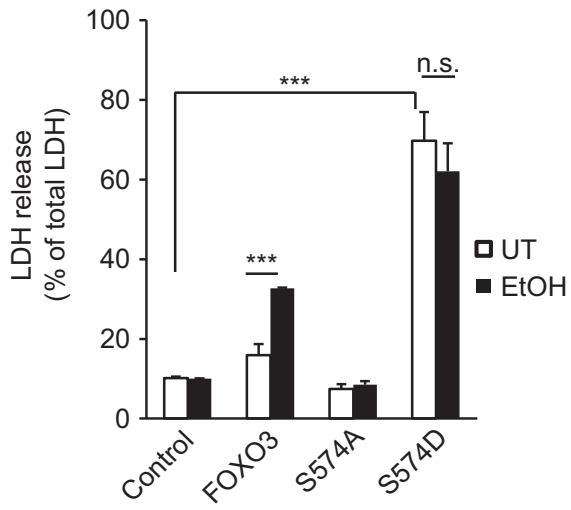

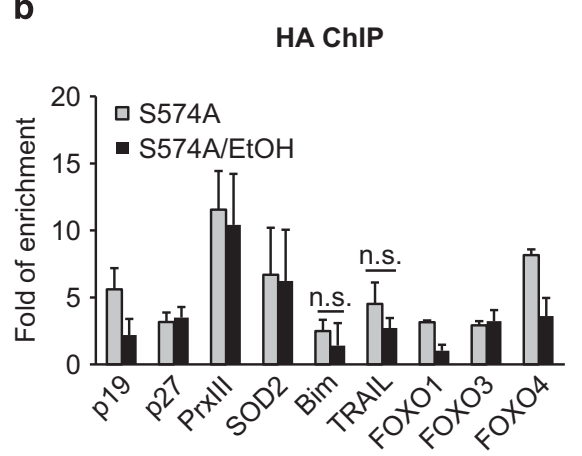

e

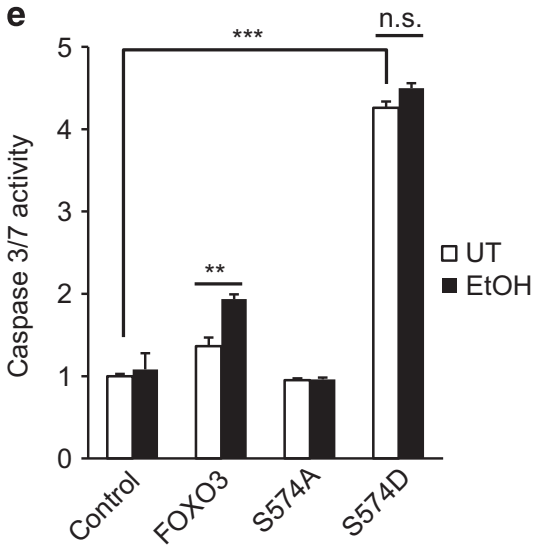

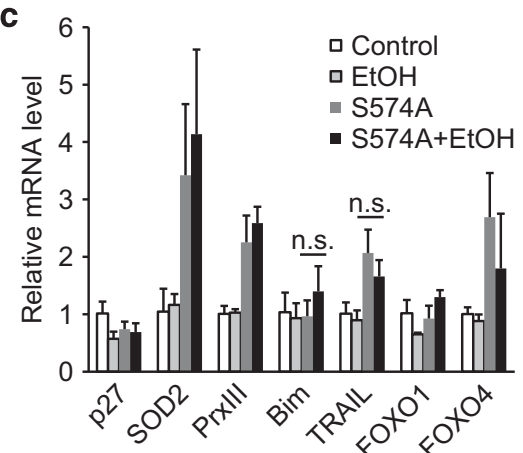

f

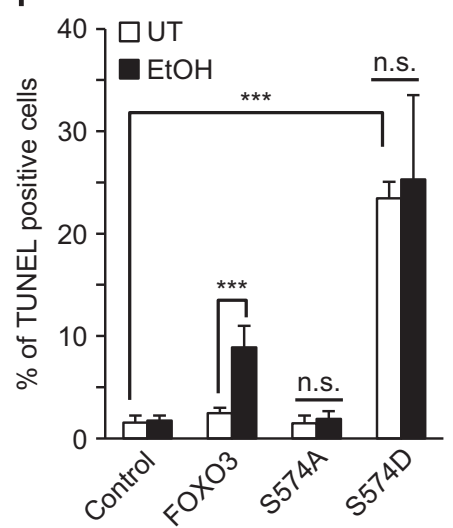

Figure 3 Apoptotic effects of p-574-FOXO3. (a) Huh7.5 cells were transfected with FOXO3 and treated with $50 \mathrm{mM} \mathrm{EtOH}$ for $48 \mathrm{~h}$. ChIP assay was performed as in Figure 1 using p-574-FOXO3 antibody. (b-c) Cells were transfected with HA-FOXO3-S-474A and treated with or without $50 \mathrm{mM} \mathrm{EtOH}$ for $48 \mathrm{~h}$. ChIP assay was performed with HA antibody (b) and mRNA expression was determined by RT-PCR (c). (d-f) Cells were transfected with HA-tagged FOXO3, FOXO3-S-547A or FOXO3 S-574D with or without EtOH treatment. Cell death was evaluated by LDH release (d), caspase activity (e) and TUNEL assay (f). Values are mean \pm S.D. of three independent experiments. ${ }^{\star \star} P<0.01$, ${ }^{* * *} P<0.001$, Student's $t$-test

combination was sufficient to induce apoptosis in the absence of $\mathrm{FOXO} / \mathrm{EtOH}$ (Figure $5 \mathrm{~d}$ ). Similarly, decreasing $\mathrm{Bcl}-2$ through FOXO3 siRNA was also sufficient to confer TRAIL-sensitive apoptosis (Figures $5 e$ and $\mathrm{f}$ ). These results indicate that the observed increase of TRAIL and decrease of $\mathrm{Bcl}-2$ are both necessary and sufficient to explain FOXO3/ EtOH-induced apoptosis.

FOXO3 mediates macrophage apoptosis. Although the above studies demonstrate the apoptotic function of $p-574-$ FOXO3, the induction of apoptosis in hepatocytes and hepatoma cells required $\mathrm{FOXO} 3$ overexpression. As FOXO3-dependent apoptosis results from an increase in TRAIL and a decrease in $\mathrm{Bcl}-2$, we reasoned that differences in basal expression of the proteins involved might influence whether FOXO3 S-574 phosphorylation induces apoptosis. To examine this issue we measured protein levels of FOXO3, $\mathrm{Bcl}-2$ and TRAIL in hepatoma cells, hepatocytes and the human monocyte/macrophage cell line, THP-1 (Figure 6a). THP-1 cells express higher levels of $\mathrm{Bcl}-2$ and $\mathrm{FOXO} 3$ and lower levels of TRAIL than hepatocytes. As alcoholic liver disease is known to involve lipopolysaccharide (LPS) release from the gut with subsequent activation of hepatic macrophages, ${ }^{27}$ we determined the impact of LPS on macrophage $\mathrm{FOXO} 3$ and apoptosis.
Figure $6 \mathrm{~b}$ shows immunofluorescence images demonstrating that LPS induces S-574 phosphorylation of FOXO3 in THP-1 cells and this phosphorylation is JNK dependent (Figure 6b). The specificity of this signal for FOXO3 was demonstrated in FOXO3 knockdown cells where LPS no longer induced the immunofluorescence signal (Figure 6c). We next performed ChIP studies using antibodies against total or p-574-FOXO3. Total FOXO3 bound to a range of promoters but LPS treatment increased binding only to the apoptosis-related genes Bcl-2 and TRAIL (Figure 6d). Before LPS stimulation, there was minimal promoter binding of $\mathrm{p}-574-\mathrm{FOXO} 3$ and we detected significant binding only for Bcl-2 and TRAIL. LPS induced >10-fold increases in the signal for these two genes without altering binding to other FOXO3 targets (Figure 6e). LPS treatment resulted in a 10-fold decrease of $\mathrm{Bcl}-2$, and a 2-fold increase of TRAIL mRNA (Figure 6f) with similar effects on protein levels (Figure 6g). LPS also induced THP-1 cell death as evidenced by LDH release (Figure 6h), TUNEL positivity (Figure 6i) and PARP cleavage (Figure 6g). Both $\mathrm{LDH}$ release and TUNEL positivity were suppressed by JNK inhibitor. LPS thus induces p-574-FOXO3 formation and generates the FOXO3-associated apoptosis phenotype characterized by decreased Bcl-2, increased TRAIL and cell death.

To determine whether LPS-induced macrophage cell death is $\mathrm{FOXO} 3$ dependent, we isolated peritoneal macrophages from WT and $\mathrm{FOXO}^{-1-}$ mice. In WT macrophages, LPS 
a

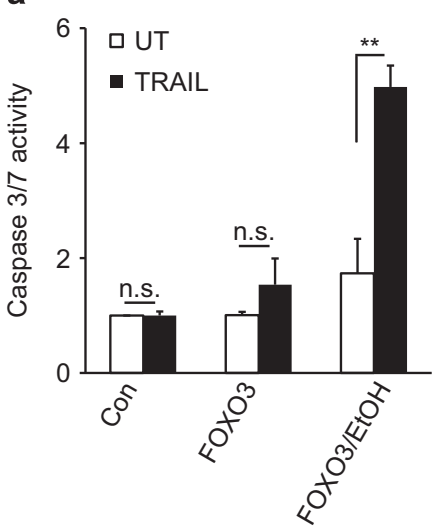

b

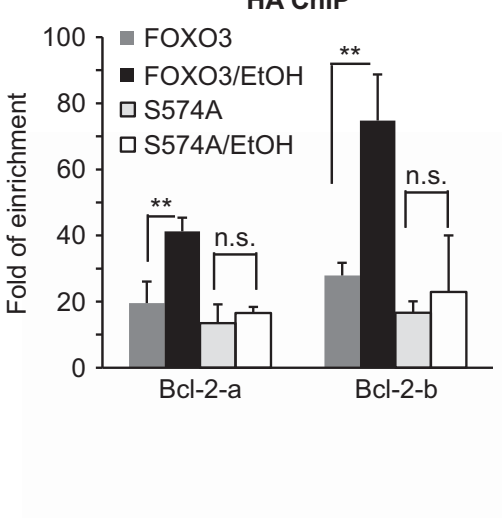

C

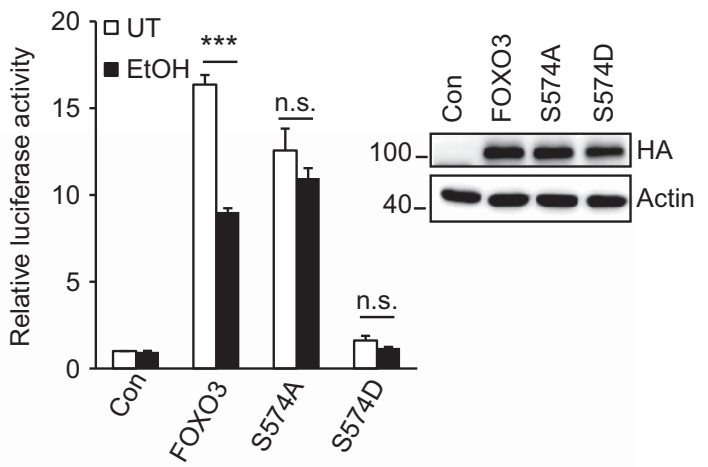

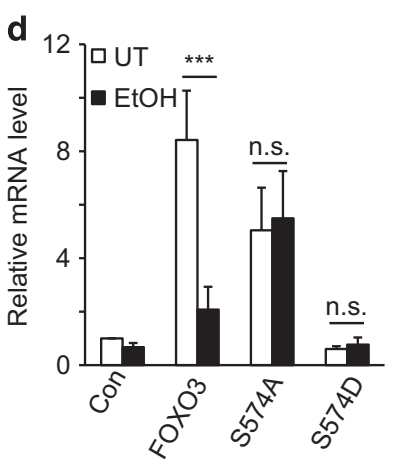

e

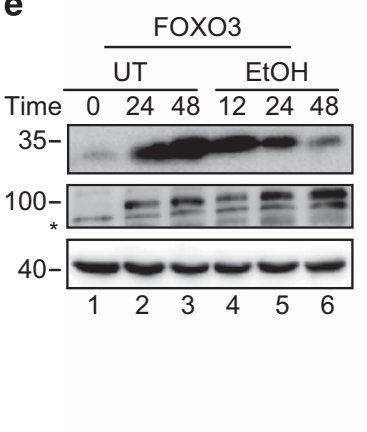

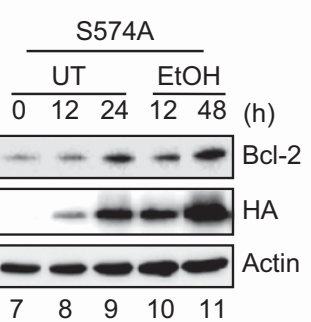
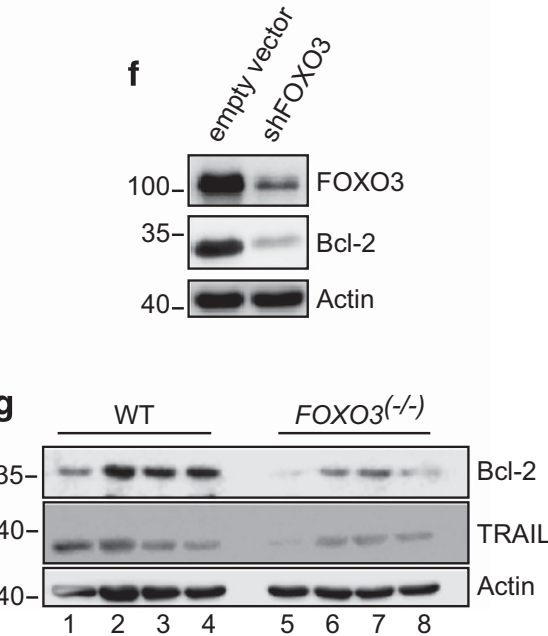

Figure 4 p-574-FOXO3 is a transcriptional repressor of Bcl-2. (a) FOXO3-transfected Huh7.5 cells were treated with $50 \mathrm{mM}$ EtOH in the absence or presence of exogenous TRAIL (100 ng/ml). Caspase $3 / 7$ activity was determined $48 \mathrm{~h}$ after treatment. (b) Cells were transfected with HA-FOXO3 or HA-FOXO3 S-574A, incubated for $16 \mathrm{~h}$ and subsequently treated with EtOH (50 mM) for an additional $24 \mathrm{~h}$. ChIP experiments were performed with HA antibody and two sets of Bcl-2 promoter primers. (c) Bcl-2 promoter luciferase assays were performed after expression of HA-tagged WT or mutant FOXO3 proteins followed by incubation with EtOH ( $50 \mathrm{mM}$ ) for an additional $48 \mathrm{~h}$. Relative HA protein expression was demonstrated by western blot. (d) Bcl-2 mRNA levels in response to FOXO3 protein expression and EtOH treatment as in (c). (e) Bcl-2 protein levels in cells that were untransfected (UT) or transfected with HA-FOXO3 (lanes 1-6) or HA-FOXO3 S-574A (lanes 7-11) with subsequent 50 mM EtOH exposure. Time is listed in hours after transfection (lanes 1-3 and 7-9) or subsequent EtOH addition to the same cultures (lanes 4-6 and 10-11). Asterisk indicates nonspecific bands. (f) Bcl-2 expression in FOXO3 knockdown cells. Huh 7.5 cells were infected with vectors coding for FOXO3-specific shRNA or empty vector. Knockdown efficiency and Bcl-2 expression level were verified by western blot. (g) Bcl-2 expression in liver homogenates from WT (lanes 1-4) and $\mathrm{FOXO}^{-/}$mice (lanes 5-8). Each lane represents a homogenate from a single mouse. Values are mean \pm S.D. of three independent experiments. ${ }^{* \star} P<0.01,{ }^{* \star *} P<0.001$, Student's $t$-test

Table 1 Effects of $\mathrm{FOXO} 3$ with and without $\mathrm{EtOH}$ on pro- and anti-apoptotic gene mRNA expression

\begin{tabular}{llrc}
\hline & Target gene & FOXO3 & FOXO3/EtOH \\
\hline Anti-apoptotic & BCL2 & 30.7 & 1.1 \\
& BIRC2 & 2.3 & 0.6 \\
& BIRC3 & 9.5 & 3.4 \\
& BNIP3L & 4.0 & 1.3 \\
Pro-apoptotic & TNFRSF1B & 23.1 & 4.0 \\
& TNF & 11.6 & 14.0 \\
& TNFRSF9 & 12.2 & 20.3 \\
& TNFRSF8 & 3.9 & 18.7 \\
& IL10 & 3.4 & 6.3
\end{tabular}

Data are expressed as mRNA fold elevation compared with Huh7.5 cells that were not transfected with $\mathrm{FOXO} 3$ or treated with $\mathrm{EtOH}$

treatment decreased $\mathrm{Bcl}-2$ and increased TRAIL mRNA (Figures $7 a$ and $b$ ), whereas $40 \%$ of the cells became TUNEL positive (Figure 7c). In FOXO3 ${ }^{-/-}$macrophages, LPS treatment had no effect on Bcl-2 or TRAIL and apoptosis was dramatically reduced. LPS also increased SOD2 mRNA but this effect was not dependent on FOXO3 (Figure 7d). Unlike the situation for alcohol treatment of FOXO3-expressing hepatoma cells, Bim mRNA was unaffected (Figure 7e).

To further explore the role of FOXO3 S-574 phosphorylation in macrophage apoptosis we used lentiviral-mediated FOXO3 shRNA to knock down FOXO3 expression in THP-1 cells. Similar to $\mathrm{FOXO}^{-1-}$ macrophages, these cells were resistant to LPS-induced apoptosis (Figure 7f). We then re-expressed either WT or mutant FOXO3 proteins in these cells (Figure 7g) and challenged them with LPS. WT FOXO3 had no effect on cell viability but its expression restored LPS sensitivity as indicated by decreased viability and increased TUNEL positivity (Figures 7h and i). FOXO3 S-574A was not able to restore LPS sensitivity. The phosphomimetic S-574D mutant reduced cell viability with or without LPS treatment. Because of rapid cell death we were not able to identify TUNEL positivity $72 \mathrm{~h}$ after FOXO3 S-574D expression. These results 
a

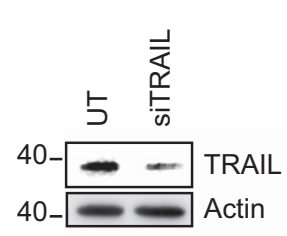

d

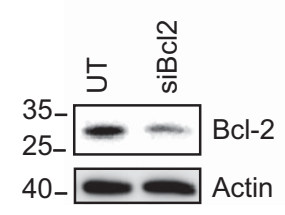

b

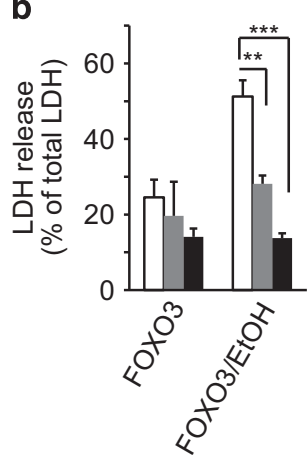

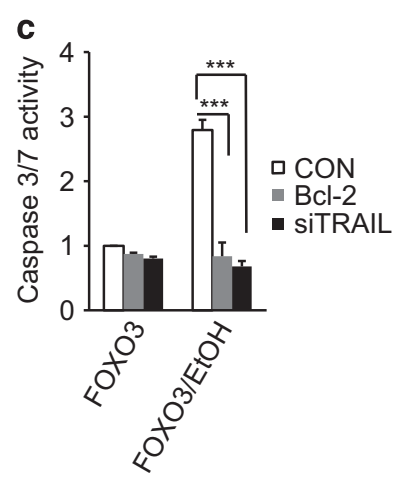

f e

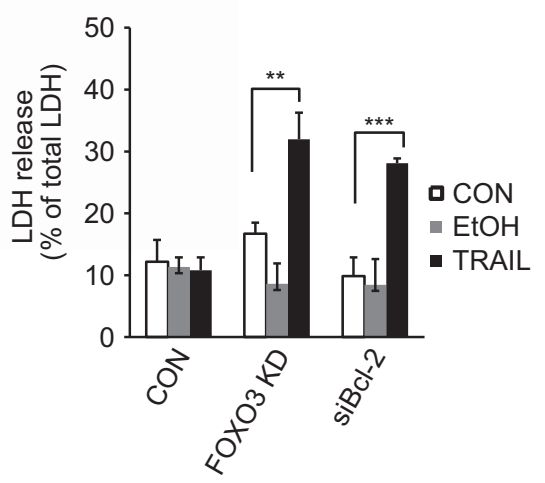

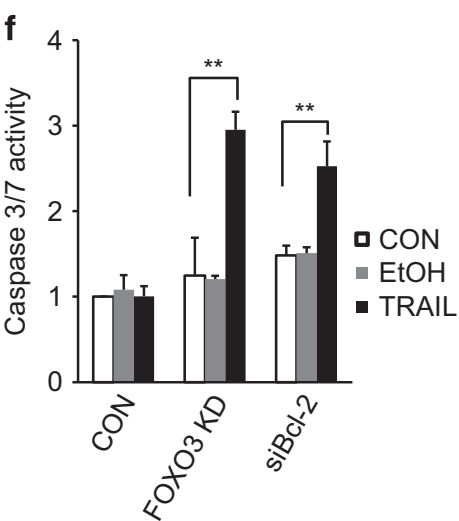

Figure 5 Bcl-2 and TRAIL determine FOXO3/EtOH-induced apoptosis. (a) Western blots in Huh7.5 cell lysates demonstrating siRNA-induced TRAIL knockdown efficiency and ability to restore EtOH-induced loss of Bcl-2 protein through Bcl-2 overexpression. (b and c) LDH release and caspase 3/7 activity induced by FOXO3 expression and EtOH treatment in cells that are deficient in TRAIL (black bars) or in cells in which Bcl-2 levels were maintained through Bcl-2 overexpression (gray bars). (d) Western blot to assess siRNA knockdown efficiency of Bcl-2. (e and f) LDH release and caspase $3 / 7$ activity induced by exogenous TRAlL ( $100 \mathrm{ng} / \mathrm{ml}$, black bars) and EtOH (gray bars) in cells that are deficient in $\mathrm{FOXO} 3$ or Bcl-2. Values are mean \pm S.D. of three independent experiments. ${ }^{* *} P<0.01,{ }^{* * *} P<0.001$, Student's $t$-test

demonstrate that S-574 phosphorylation of FOXO3 is the key event required for LPS-induced apoptosis of macrophages.

\section{Discussion}

FOXO3 can be involved in numerous cellular functions, some of which seem contradictory such as promoting both cell survival and apoptosis. ${ }^{28,29}$ Although the major mechanisms governing nuclear/cytosolic distribution and stability have been intensively investigated, much less is known about the specific mechanisms that govern transcriptional program specificity. The discovery that $p-574-F O X O 3$ is a specifically pro-apoptotic form of the protein is thus an important advance in our understanding of FOXO3.

S-574 was first reported to be a site of FOXO3 phosphorylation by Brunet et al. ${ }^{17}$ We previously observed this phosphorylated form after HCV infection ${ }^{23}$ and now have determined that it occurs after EtOH treatment of hepatocytes or LPS treatment of macrophages as well. We were able to demonstrate a strong connection between JNK activation and the appearance of p-574-FOXO3 as it was induced by activated JNK1 expression, its formation was blocked by JNK inhibitor and the time course of its appearance closely followed that of JNK activation for either LPS-treated macrophages or alcohol-treated hepatoma cells (Supplementary Figure S2). Nonetheless, we do not yet know whether FOXO3 is directly phosphorylated by JNK or by anther kinase that is activated downstream of JNK activation.

This p-574-FOXO3 selectively binds to pro-apoptotic promoters in both hepatocytes and macrophages and not to antioxidant promoters. Targeted substitutions at S-574 showed that alanine substitution was sufficient to abolish this apoptotic activity and aspartate substitution was able to induce the apoptosis program in the absence of $\mathrm{EtOH}$. This indicates that the charge at this site is the critical determinant of the pro-apoptotic function of FOXO3.

In spite of extensive information regarding the large array of FOXO3 $\mathrm{PTMs}^{7}$ there is relatively little known about how specific PTMs alter the FOXO3 transcriptional program. It has previously been shown that $\mathrm{FOXO} 3$ acetylation is related to its relative propensity to induce antioxidant versus apoptotic gene expression. ${ }^{17}$ In that study, expression or activation of the SIRT family of NAD-dependent deacetylases, particularly SIRT1, favored the antioxidant phenotype, suggesting that acetylated FOXO3 is more apoptotic whereas deacetylated FOXO3 is more antioxidant. However, specific lysine residues responsible for these effects were not determined. ${ }^{17}$ Our findings with S-574A and S-574D mutants suggest that the final arbiter of whether or not FOXO3 causes apoptosis is related to this phosphorylation event, but it is entirely possible that the ability of this serine to become phosphorylated is regulated by other protein PTMs such as lysine acetylation. This sort of multilevel control of $\mathrm{FOXO} 3$ function has been 
demonstrated for arginine methylation and Akt phosphorylation of FOXO1 where Akt phosphorylation is the final determinant of cytosolic translocation but arginine methylation of FOXO1 controls access of Akt to it substrate serine site. ${ }^{16}$
It is notable that our studies show that aspartic acid substitution of S-574 alone is sufficient to induce apoptosis, suggesting that once that residue becomes charged, changing acetylation state may not be critical. a

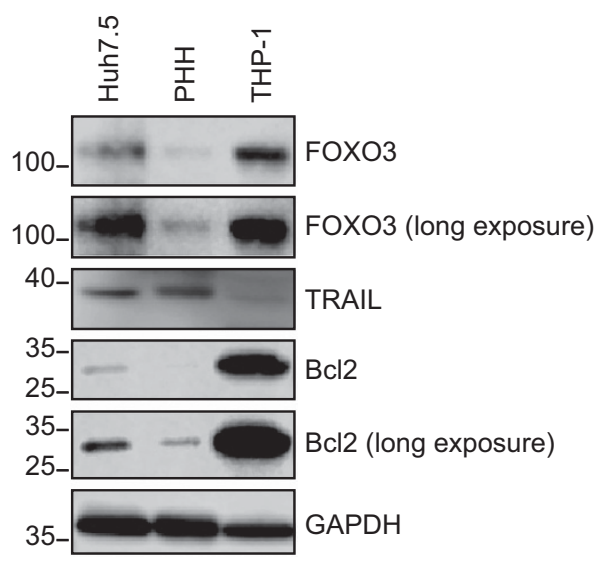

d

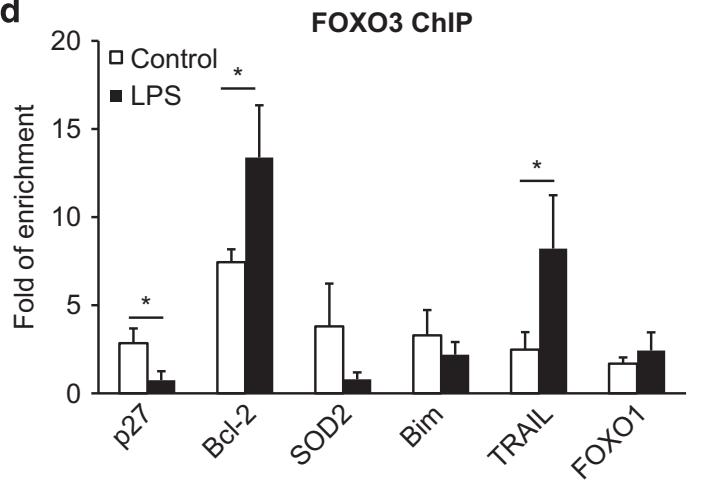

e

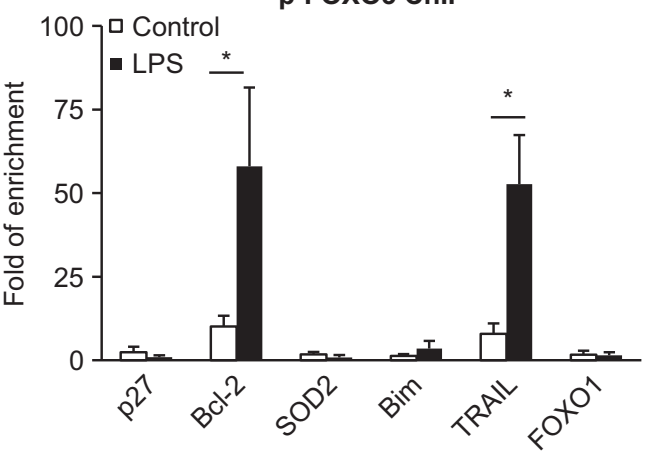

h

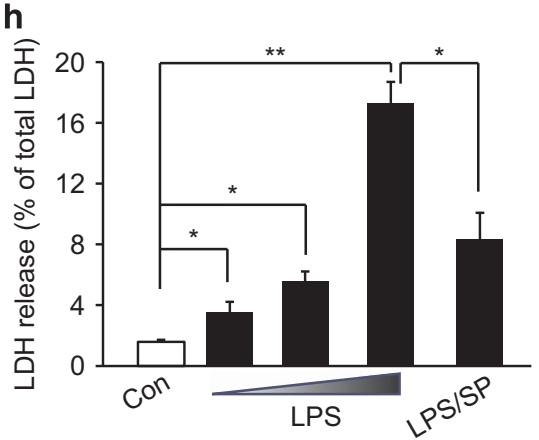

b
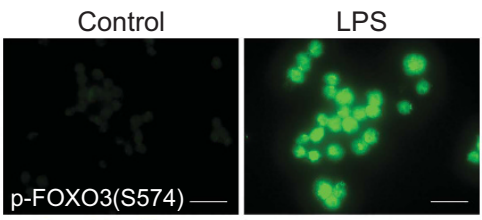

LPS/SP600125
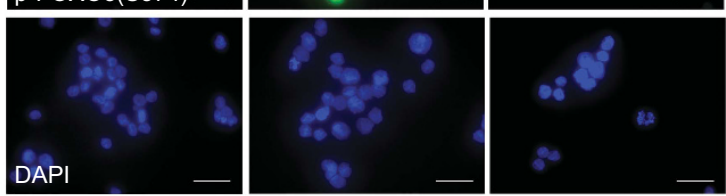

c
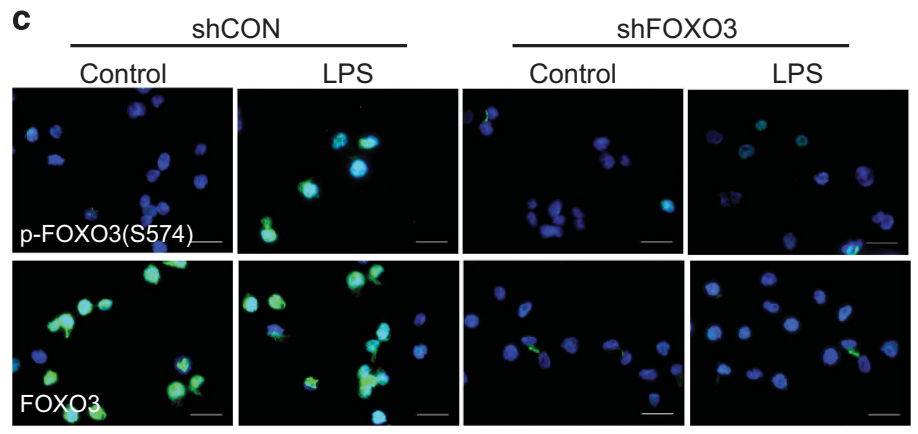

g
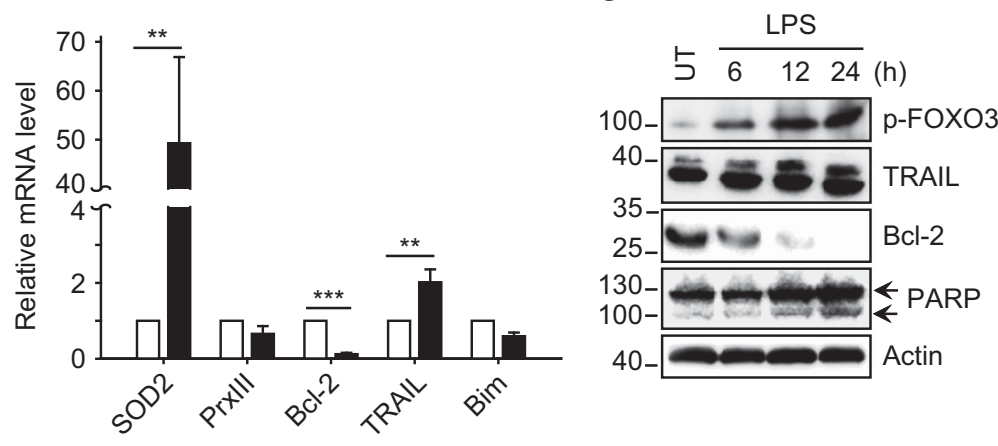

i

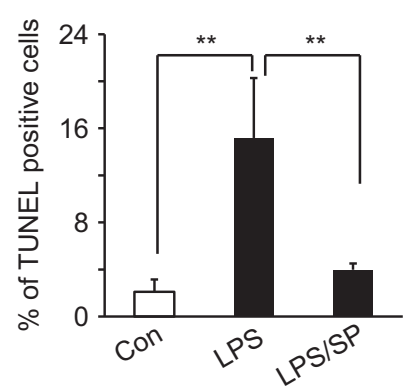


The exact identity of the gene expression changes responsible for FOXO3-dependent apoptosis has been a matter of debate. In addition to TRAIL and Bim, there are other well-described $\mathrm{FOXO} 3$ targets including the p53 target genes PUMA (p53 upregulated modulator of apoptosis) and Noxa (phorbol-12-myristate-13-acetate-induced protein 1). Although we consistently observed that p-574-FOXO3 increased BIM and TRAIL MRNA, we were not able to observe consistent changes in Bim at the protein level and thus sought out other possible causes of the apoptosis phenotype. Through a PCR array screening we were able to identify $\mathrm{Bcl}-2$ as a novel target that is regulated by FOXO3. Both the unphosphorylated form and p-574-FOXO3 bind to the $\mathrm{Bcl}-2$ promoter, but although the unphosphorylated form is a transcriptional activator, p-574-FOXO3 serves as a transcriptional repressor. In Huh7.5 cells, the combination of the increase in TRAIL and the decrease in Bcl-2 was both necessary and sufficient to produce apoptosis and an increase in Bim was not required. $\mathrm{FOXO} / \mathrm{EtOH}$-induced apoptosis could be prevented either by reducing TRAIL or increasing $\mathrm{Bcl}-2$, and apoptosis could be induced in the absence of EtOH by the combination of Bcl-2 siRNA and exogenous TRAIL exposure. Therefore, although a number of other apoptosis-related genes such as PUMA and Noxa are known to be $\mathrm{FOXO} 3$ related, ${ }^{30,31}$ the key phenotype of $\mathrm{EtOH} /$ FOXO3 apoptosis requires at the minimum, an increase in TRAIL and a decrease in Bcl-2.

We initially used Huh7.5 hepatoma cells as the system in which to investigate $\mathrm{FOXO} 3$ effects. These cells are widely used as they are permissive to cell culture infection with HCV and we previously showed that they express alcohol dehydrogenase $(\mathrm{ADH})$ and respond to alcohol. ${ }^{32}$ They were chosen for this study as previous isoelectric focusing studies showed that HCV infection and alcohol generated specific and different FOXO3 PTMs and these appeared to determine antioxidant responses. ${ }^{23}$ In this earlier study we observed that $\mathrm{HCV}$ caused a specific species of $\mathrm{FOXO} 3$ that contained S-574 phosphorylation but this particular species was not identified after EtOH treatment. This implies that the HCVinduced and $\mathrm{EtOH}$-induced p-574 phosphorylated forms of FOXO3 may differ at other sites as they have different pls.

$\mathrm{EtOH}$ induced robust S-574 phosphorylation of endogenous FOXO3 in both hepatocytes and hepatoma cells, but in both cases this was not sufficient to induce apoptosis without first overexpressing FOXO3. In contrast, macrophages undergo endogenous FOXO3 S-574 phosphorylation in response to LPS and this is sufficient to induce apoptosis. Although the reason for the different responses of these two cell types is not certain, our data suggest two possibilities. First, there may be a minimum level of FOXO3 expression below which FOXO3 phosphorylation is not able to induce apoptosis. This possibility is suggested by the observation that endogenous FOXO3 expression is considerably higher in THP-1 cells than hepatocytes or hepatoma cells (Figure 6a) and that an $80 \%$ FOXO3 knockdown in THP-1 cells was sufficient to abolish LPS-induced apoptosis (Figure 7). Alternatively, it could result from a difference in how apoptosis is regulated in different cell types. Macrophages have high expression of FOXO3 and express high levels of $\mathrm{Bcl}-2$ and low levels of TRAIL at baseline. Thus, FOXO3 phosphorylation at S-574, which suppresses Bcl-2 and increases TRAIL, is likely to dramatically alter cell death control. Hepatocytes and most hepatoma cells express relatively lower amounts of FOXO3, have relatively high basal TRAIL expression and most importantly express only very low levels of $\mathrm{Bcl}-2$. A further loss of $\mathrm{Bcl}-2$ as a result of $\mathrm{FOXO} 3$ phosphorylation is thus likely to be less consequential. After overexpression of FOXO3, however, hepatocellular $\mathrm{FOXO} 3$ levels and $\mathrm{Bcl}-2$ levels increase dramatically, thus rendering the cells sensitive to the pro-apoptotic effects of FOXO3 S-574 phosphorylation. We previously showed that $\mathrm{FOXO} 3$ is a protective factor that prevents alcohol-induced liver injury. ${ }^{32}$ The present results suggest that an effect on macrophage apoptosis might be playing a role in this protection. Understanding how $\mathrm{p}$-574FOXO3-dependent apoptosis is differentially regulated in the different cell types of the liver could provide important insights into the pathogenesis of alcoholic liver disease.

In summary, the present results show that alcohol treatment of hepatocytes or LPS treatment of macrophages induces phosphorylation of $\mathrm{FOXO} 3$ at S-574, generating a form of $\mathrm{FOXO} 3$ that can promote apoptosis through direct transcriptional activation of TRAIL, and by a previous unrecognized ability of $\mathrm{p}-574-\mathrm{FOXO} 3$ to act as a transcriptional repressor of $\mathrm{Bcl}-2$. FOXO3-dependent apoptosis occurs in macrophages in response to LPS and may occur in other cell types as well. The finding that a specific PTM is sufficient to induce a $\mathrm{FOXO} 3$ apoptosis program is one of the first demonstrations of a transcriptionally selective form of FOXO3 and opens the possibility that modifying this phosphorylation process in both positive and negative ways could be an important therapeutic approach. FOXO3-dependent apoptosis has been postulated to play a role in its ability to serve as a tumor suppressor, ${ }^{33}$ has been implicated in muscle atrophy and cardiomyopathy ${ }^{34}$ and appears to play a role in response of cancers to cytotoxic chemotherapy agents. ${ }^{35}$ Further work will be necessary to understand the factors that regulate the ability of JNK to induce phosphorylation at this site, whether other kinases perform this function as well and whether other factors ultimately determine cell fate in the presence of p-574-FOXO3.

Figure 6 Effects of LPS on FOXO3 S-574 phosphorylation, promoter binding and function in monocytes. (a) Western blots of lysates from Huh7.5 hepatoma cells, primary human hepatocytes (PHH), and human monocytic (THP-1) cells demonstrating relative protein levels of FOXO3, Bcl-2 and TRAIL. (b) Immunofluorescence for p-574-FOXO3 in THP-1 cells either without treatment, after treatment with $100 \mathrm{ng} / \mathrm{ml}$ LPS or with LPS+JNK inhibitor SP600125 $(20 \mu \mathrm{M})$. p-574-FOXO3 was determined $24 \mathrm{~h}$ after treatment by using p-FOXO3 S-574 antibody. DAPI stain indicates the presence of nuclei. Scale bars, $50 \mu \mathrm{m}$. (c) THP-1 cell immunofluorescence images for p-574-FOXO3 or total FOXO3 with or without LPS treatment in cells after infection with lentiviral shRNA constructs for either FOXO3 (shFOXO3) or scrambled control mRNA (shCON). Images are an overlay of immunofluorescence (green) and DAPI (blue). Scale bars, $50 \mu \mathrm{m}$. (d and e) THP-1 cells were cultured with or without $100 \mathrm{ng} / \mathrm{ml}$ LPS for $12 \mathrm{~h}$. ChIP assays were performed with anti-total FOXO3 or anti p-574-FOXO3 antibodies. (f and $\mathbf{g}$ ) mRNA and protein expression in untreated (UT) or LPS-treated THP-1 cells. Numbers indicate hours after LPS treatment. (h and i) LDH release and TUNEL assay for THP-1 cells treated with 10, 20 and $100 \mathrm{ng} / \mathrm{ml}$ LPS in the absence or presence of SP600125. Values are mean \pm S.D. of three independent experiments. ${ }^{*} P<0.05,{ }^{* \star} P<0.01,{ }^{* \star *} P<0.001$, Student's $t$-test 


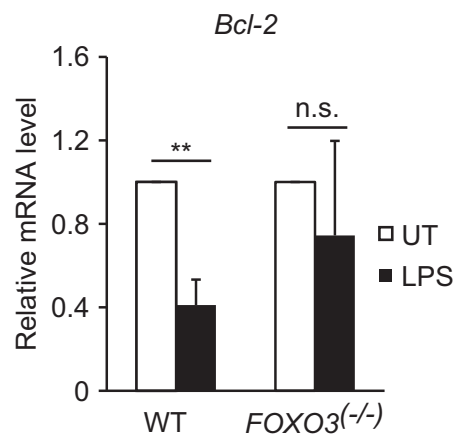

d

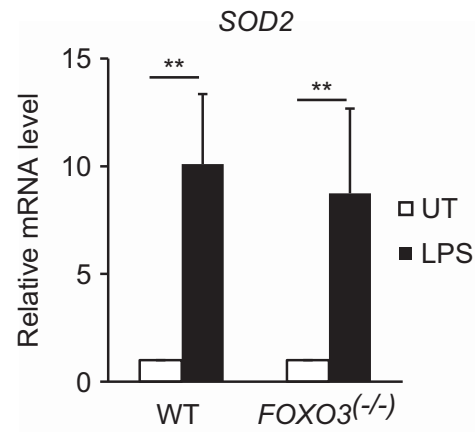

b

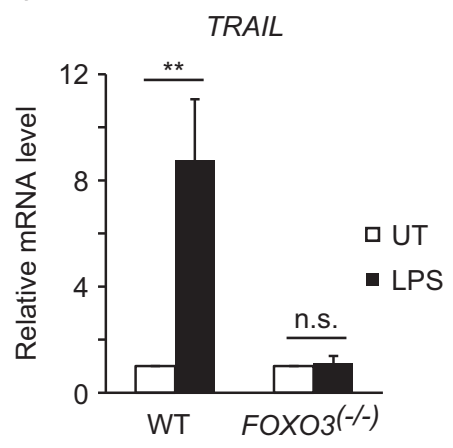

e

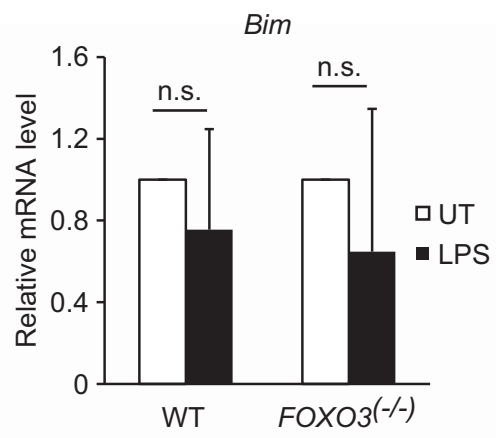

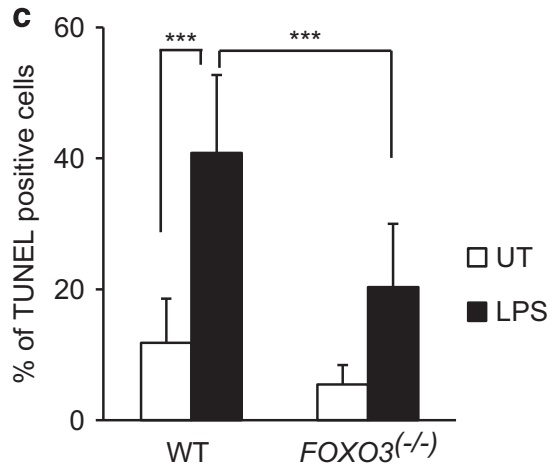

f

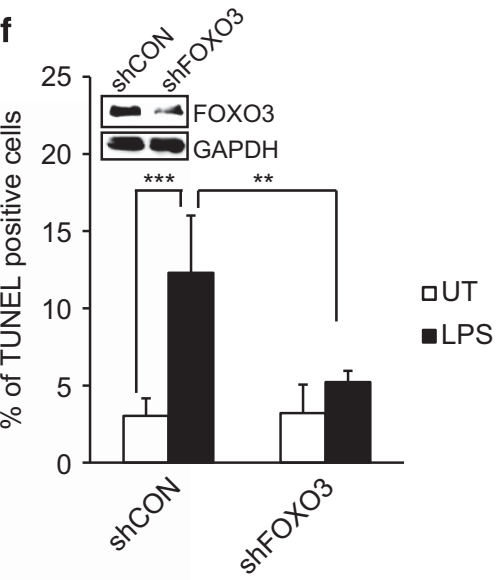

g
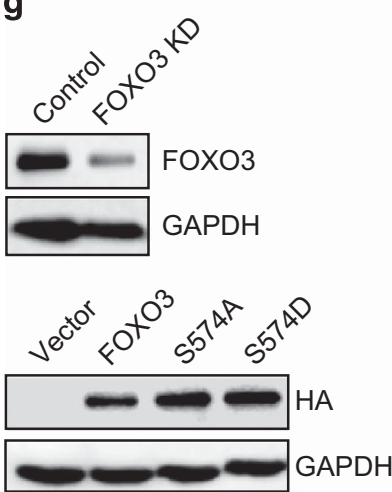

h

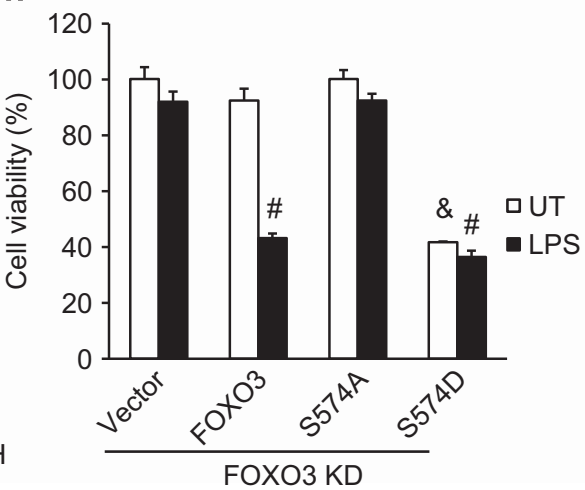

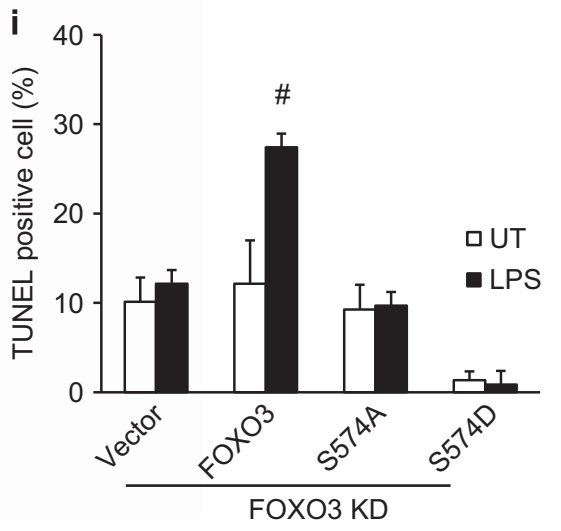

Figure 7 p-574-FOXO3-dependent macrophage apoptosis. (a and $\mathbf{b})$ Real-time RT-PCR analysis of BCl-2 and TRAIL mRNA levels in peritoneal macrophages isolated from wild-type (WT) or FOXO3 ${ }^{-1-}$ mice and subsequently treated for $24 \mathrm{~h}$ with $100 \mathrm{ng} / \mathrm{ml}$ LPS (WT $\left.n=3, \mathrm{FOXO}^{-1} n=4\right)$. (c) TUNEL assays were performed in peritoneal macrophages isolated from WT and FOXO3 ${ }^{-1}$ mice either untreated (con) or treated with $100 \mathrm{ng} / \mathrm{ml}$ LPS for $24 \mathrm{~h}(n=3$ each). (d and e) Real-time RT-PCR analysis of SOD2

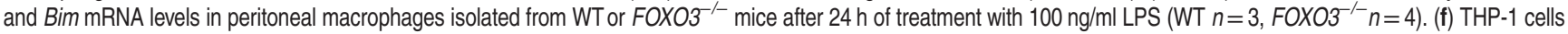
were infected with vectors coding for FOXO3-specific shRNA or empty lentiviral particles. After $48 \mathrm{~h}$, cells were either left untreated (UT) or treated with $100 \mathrm{ng} / \mathrm{ml}$ LPS for $24 \mathrm{~h}$. TUNEL assays were then performed. Values are mean \pm S.D. ${ }^{* *} P<0.01,{ }^{* \star} P<0.001$, Student's $t$-test. Inset shows western blot demonstrating magnitude of the knockdown achieved. (g, upper panel) Western blot to assess shRNA knockdown efficiency of FOXO3 in THP-1 cells after $5 \mu \mathrm{g} / \mathrm{ml}$ puromycin selection. (g, lower panel) Western blot in these same cells $48 \mathrm{~h}$ after electroporation of HA-tagged WT or mutant FOXO3 proteins. (h and i) Cell viability and TUNEL assay for FOXO3 knockdown cells electroporated with empty vector, HA-WT-FOXO3, HA-FOXO3 S-574A or HA-FOXO3 S-574D. Results are shown after $48 \mathrm{~h}$ of either no treatment (UT) or $24 \mathrm{~h}$ without treatment followed by an additional $24 \mathrm{~h}$ of treatment with $100 \mathrm{ng} / \mathrm{ml}$ LPS. Values are mean \pm S.D. ${ }^{\#} P<0.001$ versus vector/UT, ${ }^{\circledR} P<0.001$ versus vector/LPS

\section{Materials and Methods}

Cell culture, plasmids and transfection. Huh7.5 cells (provided by Dr Charles Rice, New York, NY, USA) were maintained in Dulbecco's modified Eagle's medium (Invitrogen, Grand Island, NY, USA) containing 10\% fetal bovine serum (FBS), $50 \mathrm{U} / \mathrm{ml}$ penicillin and $50 \mathrm{mg} / \mathrm{ml}$ streptomycin. Cells were treated with $50 \mathrm{mM} \mathrm{EtOH}$, and JNK inhibitor (SP600125, $20 \mu \mathrm{M}$ ) was used $4 \mathrm{~h}$ before EtOH treatment. Cells were transfected in the presence of serum-free medium (Opti-MEM, Invitrogen) by using Lipofectamine 2000 transfection reagent (Invitrogen) according to the manufacturer's instructions. pECE-HA-FOXO3, pcDNA3 Bcl-2, LB322 (Bcl-2 from ATG to -3934) and pCDNA3 Flag MKK7B2Jnk1a1 were respectively provided by M Greenberg, S Korsmeyer, L Boxervia and RJ Davis via Addgene (Cambridge, MA, USA). FOXO3 point mutation was generated by site-directed mutagenesis (Quickchange Kit, Stratagene, Santa Clara, CA, USA). For siRNA transfections, $2 \times 10^{5}$ cells were plated and cultured overnight. Thereafter, gene-specific siRNAs were transfected in the presence of Opti-MEM medium (Invitrogen) using X-tremeGENE siRNA Transfection Reagent (Roche, Indianapolis, IN, USA) 
according to the manufacturer's instructions. siRNA targeting Bcl-2 (s1915) was purchased from Invitrogen and siRNA targeting TRAIL (sc-36719) was purchased from Santa Cruz Biotechnology (Dallas, TX, USA). The lentiviral vectors coding for human FOXO3-specific shRNA (MISSION TRC shRNA TRCN0000040100, TRCN0000040098) and the control vector pLKO.1 were obtained from SigmaAldrich (St. Louis, MO, USA). THP-1 cells were purchased from ATCC (Manassas, VA, USA) and maintained in RPMI-1640 Medium (Invitrogen) containing 10\% FBS and $0.05 \mathrm{mM}$ 2-mercaptoethanol. For preparation of $\mathrm{FOXO} 3$ knockdown cells, THP-1 cells were transduced with lentiviral FOXO3 shRNA supernatants supplemented with polybrene $(4 \mu \mathrm{g} / \mathrm{ml})$. Pools of shRNA-transduced cells were selected by adding $5 \mu \mathrm{g} / \mathrm{ml}$ puromycin (Gibco/Invitrogen, Grand Island, NY, USA) to the culture medium. FOXO3 expression level was determined by western blot $72 \mathrm{~h}$ after infection. Expression of $\mathrm{FOXO} 3$ or $\mathrm{FOXO} 3$ mutants in knockdown cells was performed by electroporation. $4 \times 10^{6}$ FOXO3 stable knockdown THP-1 cells were resuspended in $400 \mu \mathrm{l}$ serum-free RPMI media and incubated with $10 \mu \mathrm{g}$ DNA for $5 \mathrm{~min}$ on ice before being electroporated at $140 \mathrm{~V}, 1000 \mu \mathrm{F}$. Following electroporation, $600 \mu$ l complete RPMI media were added to the cells that were kept on ice for $15 \mathrm{~min}$, and then grown in $5 \mathrm{ml}$ media for $48 \mathrm{~h}$.

Isolation and culture of primary human hepatocytes. Primary human hepatocytes were freshly isolated from liver resections by the Cell Isolation Core of the Department of Pharmacology at the University of Kansas Medical Center (Kansas City, KS, USA). All human tissues were obtained with informed consent from each patient according to ethical and institutional guidelines. The study was approved by the institutional review board at the University of Kansas Medical Center. Cells were isolated using a multi-step collagenase procedure as described in detail previously. ${ }^{36}$ Media consisted of Williams' Medium E (Life Technologies, Grand Island, NY, USA) supplemented with L-glutamine (2 mM) (Life Technologies), HEPES $(10 \mathrm{mM})$, insulin $\left(10^{-7} \mathrm{M}\right)$, dexamethasone $\left(10^{-7} \mathrm{M}\right)$, penicillin $(100 \mathrm{U} / \mathrm{ml})$, streptomycin $(100 \mu \mathrm{g} / \mathrm{ml})$ and amphotericin $\mathrm{B}(0.25 \mu \mathrm{g} / \mathrm{ml})$. The hepatocytes were brought to a concentration of $0.5 \times 10^{6}$ cells $/ \mathrm{ml}$ in Williams' Medium E, as described above, plus $5 \%$ bovine calf serum. The hepatocytes were then seeded on collagen-coated plates and allowed to attach in a humidified $37^{\circ} \mathrm{C}$, $5 \% \mathrm{CO}_{2}$ incubator for $12 \mathrm{~h}$ and then treated with $50 \mathrm{mM} \mathrm{EtOH}$ for indicated times.

Mouse strains. $\mathrm{FOXO}^{-1-}$ mice were provided by $\mathrm{Dr}$ Kana Miyamoto (Keio University, Tokyo, Japan) and were generated as previously described. ${ }^{37}$ Heterozygotes were bred together, obtaining both knockout and WT littermates. All mice were housed in a temperature-controlled, specific pathogen-free environment with 12-h light/dark cycles and fed regular mouse chow and water ad libitum. All animal handling procedures were approved by the institutional animal care and use committees at the University of Kansas Medical Center.

Isolation of mouse peritoneal macrophages. Primary peritoneal macrophages were isolated as described previously. ${ }^{38} \mathrm{C} 57 \mathrm{BL} / 6$ or $\mathrm{FOXO}^{-1-}$ mice at 5 weeks of age were killed by $\mathrm{CO}_{2}$ asphyxiation. Briefly, $10 \mathrm{ml}$ of sterile phosphate buffered saline (PBS) was injected into the caudal half of the peritoneal cavity using a 25-gauge needle (beveled side up), following by shaking the entire body for $10 \mathrm{~s}$. Saline containing resident peritoneal cells was collected and cells were plated on uncoated tissue culture plates and incubated for $60 \mathrm{~min}$ at $37^{\circ} \mathrm{C}$. Nonadherent cells were removed by washing five times with warm PBS. Macrophages were maintained in RPMI medium (Invitrogen) containing 10\% FBS overnight and then treated with or without LPS (LPS from Escherichia coli 026:B6, Sigma-Aldrich) for additional $24 \mathrm{~h}$ before being processed for analysis.

Immunofluorescence. Cells grown on coverslips were washed in PBS three times and fixed for $10 \mathrm{~min}$ in $4 \%$ paraformaldehyde in PBS at room temperature. For indirect immunofluorescence, fixed cells were permeabilized in $1 \%$ Triton X-100 in PBS for $5 \mathrm{~min}$ at room temperature. The coverslips were inverted and touched to $40 \mu \mathrm{l}$ droplets of blocking buffer (4\% goat serum and $1 \%$ bovine serum albumin in PBS-Tween, $0.05 \%$ ) on a clean parafilm sheet for $45 \mathrm{~min}$ at room temperature. Cells were then incubated in PBS with rabbit anti-FOXO3 antibody (75D8) or rabbit anti-p-FOXO3 S-574 for $1 \mathrm{~h}$ at room temperature. After washing with PBS, coverslips were incubated with Alexa Fluor 488-conjugated goat anti-rabbit $\lg G(1: 5000$; Molecular Probes, Waltham, MA, USA) for $1 \mathrm{~h}$ in the dark at room temperature. Coverslips were additionally incubated with DAPI for $20 \mathrm{~min}$ at room temperature to stain nuclear DNA. Images were acquired by using Nikon Eclipse Ti microscope (Nikon Americas Inc., Melville, NY, USA).
ChIP assay. Huh7.5 cells $\left(1.5 \times 10^{7}\right)$ were transfected with the indicated constructs by Lipofectamine 2000 according to the manufacturer's instructions (Invitrogen). At $24 \mathrm{~h}$ after transfection, cells were treated with $50 \mathrm{mM} \mathrm{EtOH}$ for an additional $48 \mathrm{~h}$. For endogenous FOXO3 ChIP experiments, Huh7.5 cell $\left(1.5 \times 10^{7}\right)$ were treated with $50 \mathrm{mM} \mathrm{EtOH}$ for $48 \mathrm{~h}$. DNA and proteins were crosslinked by the addition of formaldehyde to a final concentration of $1 \%$ for 10 min before harvesting. The crosslinking reaction was stopped by adding glycine at $0.125 \mathrm{~mol} / \mathrm{l}$ final concentration for $5 \mathrm{~min}$ at room temperature. Flasks were rinsed twice with ice-cold $1 \times$ PBS and cells were scraped off the plates, resuspended in cell lysis buffer (10 mM Tris- $\mathrm{HCl}$ (pH 8.0), $10 \mathrm{mM} \mathrm{NaCl}, 3 \mathrm{mM} \mathrm{MgCl}, 0.5 \% \mathrm{NP}-40$ and protease inhibitors) and incubated on ice for $15 \mathrm{~min}$. The cell suspension was vortexed briefly every $5 \mathrm{~min}$ to aid in release of nuclei. Nuclei were collected by centrifuge, resuspended in nuclei lysis buffer ( $1 \% \mathrm{SDS}, 5 \mathrm{mmol} / / \mathrm{EDTA}, 50 \mathrm{mmol} / \mathrm{l}$ Tris- $\mathrm{HCl}(\mathrm{pH} 8.0)$ and protease inhibitor) and sonicated to generate chromatin to an average length of $\sim 200$ to $600 \mathrm{bp}(10 \times 15 \mathrm{~s}$ at $55 \%$ maximum potency). After centrifugation at 14000 r.p.m. for $10 \mathrm{~min}$ at $4^{\circ} \mathrm{C}$, samples $(2-4 \mathrm{mg}$ of protein extracts) were immunoprecipitated overnight at $4^{\circ} \mathrm{C}$ with $1 \mu \mathrm{g}$ anti-HA ChIP-grade antibody (Abcam, Cambridge, MA, USA) or $3 \mu \mathrm{l}$ anti-FOXO3 (clone 75D8 from Cell Signaling Technology, Danvers, MA, USA). Rabbit IgG was used as a negative control of immunoprecipitation. One percent of supernatant from the immunoprecipitation was saved as total input of chromatin and was processed with the eluted immunoprecipitates beginning at the crosslink reversal step. Next, $10 \mu \mathrm{l}$ magnetic beads (Dynabeads M-280 Sheep anti Rabbit IgG, Invitrogen) were added into each sample and incubated at $4{ }^{\circ} \mathrm{C}$ for $4 \mathrm{~h}$ with rotation. Immunoprecipitates were washed with ChIP Low Salt Buffer (0.1\% SDS, 1\% Triton-100, 2 mM EDTA, 50 mM Hepes, pH 7.5, $150 \mathrm{mM} \mathrm{NaCl}$ ), ChIP High Salt Buffer (0.1\% SDS, $1 \%$ Triton-100, $2 \mathrm{mM}$ EDTA, $50 \mathrm{mM}$ Hepes, pH 7.5, $500 \mathrm{mM} \mathrm{NaCl})$, ChIP LiCl Buffer (0.25 M LiCl, $0.5 \%$ NP-40, $0.5 \%$ sodium deoxycholate, $1 \mathrm{mM}$ EDTA, $10 \mathrm{mM}$ Tris-HCl, pH 8.0) and TE buffer (10 mM Tris- $\mathrm{HCl}, 1 \mathrm{mM}$ EDTA). Immunocomplexes were eluted with $90 \mu \mathrm{l}$ elution buffer ( $1 \% \mathrm{SDS}, 50 \mathrm{mmol} / \mathrm{NaHCO}$ ) and $10 \mu \mathrm{g}$ of RNase A was added to the pooled eluates; crosslinks were reverted by incubation at $65^{\circ} \mathrm{C}$ for at least $6 \mathrm{~h}$. Samples were added with $1 \mu \mathrm{l}$ of $20 \mu \mathrm{g} / \mu \mathrm{l}$ proteinase $\mathrm{K}$ and incubated for $2 \mathrm{~h}$ at $45^{\circ}$ C. After incubation at $95^{\circ} \mathrm{C}$ for $10 \mathrm{~min}$, samples were purified used Qiagen PCR purify kit (Hilden, Germany). DNA samples were amplified with target promoterspecific primers using SYBR Green quantitative PCR analysis (Applied Biosystems, Waltham, MA, USA). Primers and probe sequences are listed in Supplementary Table S1.

Real-time PCR. RNA was extracted and purified from cultured hepatoma cells using the TRI reagent from Sigma according to the manufacturer's instructions. CDNA was generated with the random primer method using the RNA reverse transcription kit (Applied Biosystems). Quantitative RT-PCR was performed in a CFX96 real-time system (Bio-Rad, Hercules, CA, USA) using specific sense and antisense primers in $25 \mu \mathrm{l}$ reaction volumes containing $12.5 \mu \mathrm{l}$ SYBR Green PCR master mix (Applied Biosystems), $10.5 \mu \mathrm{l}$ of $1 \mu \mathrm{mol} / \mathrm{l}$ primer stock and $2 \mu \mathrm{l}$ of CDNA ( $1: 10$ diluted). The amplification consisted of an initial incubation of $95^{\circ} \mathrm{C}$ for 5 min (hot start), following by 50 amplification cycles $\left(15 \mathrm{~s}\right.$ at $95^{\circ} \mathrm{C}, 30 \mathrm{~s}$ at $55^{\circ} \mathrm{C}$ and $30 \mathrm{~s}$ at $72{ }^{\circ} \mathrm{C}$ ) and a final melting curve from $55^{\circ} \mathrm{C}$ to $95^{\circ} \mathrm{C}$. Primer sequences are presented in Supplementary Materials.

Apoptosis array analysis. Huh7.5 cell were transfected with HA-FOXO3 by Lipofectamine 2000 according to the manufacturer's instructions (Invitrogen). At $24 \mathrm{~h}$ after transfection, cells were treated with $50 \mathrm{mM}$ EtOH for an additional $48 \mathrm{~h}$. Cells were washed twice with PBS, total cellular RNA was isolated and CDNA was generated as discussed above. cDNA samples were then assayed using the Apoptosis RT2 Profiler PCR Array (Qiagen cat. no. PAHS-012Z) according to the manufacturer's instructions. Raw CT values were exported from the real-time instrument software, and analyzed using the $\Delta \Delta C T$ method. Data were present as mRNA fold elevation compared with Huh7.5 cells that were not transfected with FOXO3 or treated with EtOH.

Measurement of luciferase activity, LDH release and caspase 3/7 activity. After co-transfection of the two luciferase plasmids, both firefly and Renilla luciferase activities were measured sequentially from a single aliquot of cell lysate using the Dual-Glo Luciferase Reporter Assay System (Promega, Madison, WI, USA) according to the manufacturer's instructions. Relative Renilla luciferase light output was normalized to firefly luciferase output. LDH release and total LDH were determined using TOX7 kit (Sigma-Aldrich) according to the manufacturer's instructions. The absorbance was determined at $490 \mathrm{~nm}$. The present data were calculated by dividing 
the amount released LDH into the media by the total LDH for each experimental group Caspase 3/7 activity was determined using Caspase-Glo 3/7 Assay Systems (Promega) according to the manufacturer's instructions. Data were presented as mean \pm S.E. Statistical significance was calculated using Student's $t$-test.

TUNEL assay. Cells were fixed with $4 \%$ paraformaldehyde at room temperature for $10 \mathrm{~min}$ at room temperature. After a PBS rinse, cells were stained using the DeadEND Fluorometric TUNEL System (Promega) according to the manufacturer's instructions. Quantification of TUNEL staining was performed by examining five randomly selected fields by an investigator who was blinded to sample identity.

Western blots. Whole-cell lysates were prepared from cells that had been washed and harvested by centrifugation in PBS pH 7.5. Cell pellets were resuspended in RIPA buffer that contained $50 \mathrm{mM}$ Tris, $\mathrm{pH} 7.5,150 \mathrm{mM}$ sodium chloride, $1 \%$ NP- $40,0.2 \%$ SDS, $0.5 \%$ sodium deoxycholate, $0.1 \mathrm{mM}$ EDTA and $1 \%$ protease and phosphatase inhibitors (Sigma-Aldrich). Lysates were centrifuged at 14000 r.p.m. for $15 \mathrm{~min}$; supernatants were collected and protein concentration was measured using the Bio-Rad protein assay kit (Bio-Rad). Cell lysates $(25 \mu \mathrm{g})$ were separated by $10 \%$ SDS-PAGE and transferred to polyvinylidene difluoride membranes (Immobilon-P membranes; Millipore, Billerica, MA, USA). Membranes were blocked with blocking buffer ( $5 \%$ skim milk, $0.1 \%$ Tween-20 in PBS) for $1 \mathrm{~h}$ at room temperature. After incubation with appropriate primary antibodies overnight at $4^{\circ} \mathrm{C}$, membranes were then incubated with horseradish peroxidase-conjugated secondary antibodies, detected using the Electrochemiluminescence Plus Western Blotting Detection System (Amersham Biosciences, Piscataway, NJ, USA) with the ODYSSEY Fc, Dual-Mode Imaging system (Li-COR, Lincoln, NE, USA).

Antibodies. A custom p-FOXO3-S-574 rabbit polyclonal antibody was generated by Epitomics using the peptide SAKHQQQS(PO3H2)PVSQSM for immunization. Phospho-specific antibodies were subsequently purified through antigen affinity columns. Anti-HA antibody (ab9110) was purchased from Abcam. Anti-FOXO1 (C29H4), anti-FOXO4 (9472), anti-FOXO3 (75D8), anti-Bcl2 (50D3), anti-TRAIL (C92B9), anti-Bim (C34C5), anti-p27 (2552) and anti-PARP (9542) were purchased from Cell Signaling Technology. Anti-PrxllI was purchased from Upstate (Lake placid, NY, USA). Anti-SOD2 (FL-222) and anti-TRAIL (H-257) were purchased from Santa Cruz Biotechnology. Anti-actin (AC-15) and Anti-Flag (M2) were purchased from Sigma-Aldrich.

Chemicals. SP600125 (Cell Signaling Technology) was solubilized in dimethyl sulfoxide (DMSO) and filter sterilized before use. LPS from E. coli 026:B6 (SigmaAldrich), TRAIL-R1 (human):Fc (human) and TRAIL-R2 (human):Fc (human) (Enzo Life Science, Farmingdale, NY, USA) were solubilized in PBS and filter sterilized before use.

\section{Conflict of Interest}

The authors declare no conflict of interest.

Acknowledgements. This study was supported by grant AA012863 from the National Institute on Alcoholism and Alcohol Abuse, grants P20 GM103418 and P20 GM103549 from the National Institute of General Medical Sciences from the National Institutes of Health and a fellowship grant from the Biomedical Research Training Program of the University of Kansas Medical Center to ZL. The human hepatocytes used in this study were derived from samples provided by the University of Kansas Liver Center Tissue Bank. We thank Drs. Jameson Forster, Tim Schmitt and Bashar Abdulkarim for their assistance in obtaining these specimens and Dr. Michele Pritchard for helpful discussions. Supplementary Information accompanies this paper on Cell Death and Differentiation website (http://www.nature.com/cdd).

1. Sedding DG. FoxO transcription factors in oxidative stress response and ageing-a new fork on the way to longevity? Biol Chem 2008; 389: 279-283.

2. van der Horst $A$, Burgering BM. Stressing the role of FoxO proteins in lifespan and disease. Nat Rev Mol Cell Biol 2007; 8: 440-450.

3. Dijkers PF, Medema RH, Pals C, Banerii L, Thomas NS, Lam EW et al. Forkhead transcription factor FKHR-L1 modulates cytokine-dependent transcriptional regulation of p27 (KIP1). Mol Cell Biol 2000; 20: 9138-9148.
4. Tran $\mathrm{H}$, Brunet A, Grenier JM, Datta SR, Fornace AJ Jr, DiStefano PS et al. DNA repair pathway stimulated by the forkhead transcription factor FOXO3a through the Gadd45 protein. Science 2002; 296: 530-534.

5. Chung YW, Kim HK, Kim IY, Yim MB, Chock PB. Dual function of protein kinase C (PKC) in 12-0-tetradecanoylphorbol-13-acetate (TPA)-induced manganese superoxide dismutase (MnSOD) expression: activation of CREB and FOXO3a by PKC-alpha phosphorylation and by PKC-mediated inactivation of Akt, respectively. J Biol Chem 2011; 286: 29681-29690.

6. Hagenbuchner J, Kuznetsov A, Hermann M, Hausott B, Obexer P, Ausserlechner MJ. FOXO3-induced reactive oxygen species are regulated by BCL2L11 (Bim) and SESN3. J Cell Sci 2012; 125: 1191-1203.

7. Calnan DR, Brunet A. The FoxO code. Oncogene 2008; 27: 2276-2288.

8. Brunet A, Bonni A, Zigmond MJ, Lin MZ, Juo P, Hu LS et al. Akt promotes cell survival by phosphorylating and inhibiting a Forkhead transcription factor. Cell 1999; 96: 857-868.

9. Yang JY, Zong CS, Xia W, Yamaguchi H, Ding Q, Xie X et al. ERK promotes tumorigenesis by inhibiting FOXO3a via MDM2-mediated degradation. Nat Cell Biol 2008; 10: 138-148.

10. Su JL, Cheng X, Yamaguchi H, Chang YW, Hou CF, Lee DF et al. FOXO3a-dependent mechanism of E1A-induced chemosensitization. Cancer Res 2011; 71: 6878-6887.

11. Yoo H, Lee YS, Lee S, Kim S, Kim TY. Pachastrissamine from Pachastrissa sp. inhibits melanoma cell growth by dual inhibition of Cdk2 and ERK-mediated FOXO3 downregulation. Phytother Res 2012; 26: 1927-1933.

12. van der Horst $A$, de Vries-Smits AM, Brenkman AB, van Triest MH, van den Broek N, Colland $\mathrm{F}$ et al. FOXO4 transcriptional activity is regulated by monoubiquitination and USP7/HAUSP. Nat Cell Biol 2006; 8: 1064-1073.

13. Lehtinen MK, Yuan Z, Boag PR, Yang Y, Villén J, Becker EB et al. A conserved MST-FOXO signaling pathway mediates oxidative-stress responses and extends life span. Cell 2006; 125: $987-1001$

14. Davila D, Connolly NM, Bonner H, Weisová P, Dussmann H, Concannon CG et al. Two-step activation of FOXO3 by AMPK generates a coherent feed-forward loop determining excitotoxic cell fate. Cell Death Differ 2012; 19: 1677-1688.

15. Essers MA, Weijzen S, de Vries-Smits AM, Saarloos I, de Ruiter ND, Bos JL et al. FOXO transcription factor activation by oxidative stress mediated by the small GTPase Ral and JNK. EMBO J 2004; 23: 4802-4812.

16. Yamagata $\mathrm{K}$, Daitoku $\mathrm{H}$, Takahashi $\mathrm{Y}$, Namiki $\mathrm{K}$, Hisatake $\mathrm{K}$, Kako $\mathrm{K}$ et al. Arginine methylation of FOXO transcription factors inhibits their phosphorylation by Akt. Mol Cell 2008; 32: 221-231.

17. Brunet A, Sweeney LB, Sturgill JF, Chua KF, Greer PL, Lin Y et al. Stress-dependent regulation of FOXO transcription factors by the SIRT1 deacetylase. Science 2004; 303 : 2011-2015.

18. Tikhanovich I, Cox J, Weinman SA. Forkhead box class 0 transcription factors in liver function and disease. J Gastroenterol Hepatol 2013; 28: 125-131.

19. Tseng AH, Wu LH, Shieh SS, Wang DL. SIRT3 interactions with FOXO3 acetylation, phosphorylation and ubiquitinylation mediate endothelial cell responses to hypoxia. Biochem J 2014; 464: 157-168.

20. Wang F, Chan $\mathrm{CH}$, Chen K, Guan X, Lin HK, Tong Q. Deacetylation of FOXO3 by SIRT1 or SIRT2 leads to Skp2-mediated FOXO3 ubiquitination and degradation. Oncogene 2012; 31: $1546-1557$.

21. Eijkelenboom A, Mokry M, de Wit E, Smits LM, Polderman PE, van Triest MH et al. Genomewide analysis of FOXO3 mediated transcription regulation through RNA polymerase ॥ profiling. Mol Syst Biol 2013; 9: 638.

22. Keniry M, Mokry M, de Wit E, Smits LM, Polderman PE, van Triest MH et al. Survival factor NFIL3 restricts FOXO-induced gene expression in cancer. Genes Dev 2013; 27: 916-927.

23. Tikhanovich I, Kuravi S, Campbell RV, Kharbanda KK, Artigues A, Villar MT et al. Regulation of FOXO3 by phosphorylation and methylation in hepatitis $\mathrm{C}$ virus infection and alcohol exposure. Hepatology 2014; 59: 58-70.

24. LeBlanc HN., Ashkenazi A. Apo2L/TRAIL and its death and decoy receptors. Cell Death Differ 2003; 10: 66-75.

25. Feldmann G. Liver apoptosis. J Hepatol 1997; 26(Suppl 2): S1-S11.

26. Skopelitou A, Hadjiyannakis M, Alexopoulou V, Krikoni O, Kamina S, Agnantis N et al. Topographical immunohistochemical expression of bcl-2 protein in human liver lesions. Anticancer Res 1996; 16: 975-978.

27. Thurman RG II. Alcoholic liver injury involves activation of Kupffer cells by endotoxin. Am J Physiol 1998; 275: G605-G611.

28. Zhang X, Tang N, Hadden TJ, Rishi AK. Akt, FoxO and regulation of apoptosis. Biochim Biophys Acta 2011; 1813: 1978-1986.

29. Burgering BM, Medema RH. Decisions on life and death: FOXO Forkhead transcription factors are in command when PKB/Akt is off duty. J Leukoc Biol 2003; 73: 689-701.

30. You H, Pellegrini M, Tsuchihara K, Yamamoto K, Hacker G, Erlacher M et al. FOXO3adependent regulation of Puma in response to cytokine/growth factor withdrawal. J Exp Med 2006; 203: 1657-1663.

31. Obexer P, Geiger K, Ambros PF, Meister B, Ausserlechner MJ. FKHRL1-mediated expression of Noxa and Bim induces apoptosis via the mitochondria in neuroblastoma cells. Cell Death Differ 2007; 14: 534-547.

32. Tumurbaatar B, Tikhanovich I, Li Z, Ren J, Ralston R, Kuravi S et al. Hepatitis C and alcohol exacerbate liver injury by suppression of FOXO3. Am J Pathol 2013; 183 : 1803-1814. 
33. Greer EL, Brunet A. FOXO transcription factors at the interface between longevity and tumor suppression. Oncogene 2005; 24: 7410-7425.

34. Schips TG, Wietelmann A, Höhn K, Schimanski S, Walther P, Braun T et al. FoxO3 induces reversible cardiac atrophy and autophagy in a transgenic mouse model. Cardiovasc Res 2011; 91: 587-597.

35. Wilson MS, Brosens JJ, Schwenen HD, Lam EW. FOXO and FOXM1 in cancer: the FOXO-FOXM1 axis shapes the outcome of cancer chemotherapy. Curr Drug Targets 2011; 12: 1256-1266.
36. Xie Y, Kuravi S, Campbell RV, Kharbanda KK, Artigues A, Villar MT et al. Mechanisms of acetaminophen-induced cell death in primary human hepatocytes. Toxicol Appl Pharmacol 2014; 279: 266-274.

37. Miyamoto K, Araki KY, Naka K, Arai F, Takubo K, Yamazaki S et al. Foxo3a is essential for maintenance of the hematopoietic stem cell pool. Cell Stem Cell 2007; 1: 101-112.

38. Davies JQ, Gordon S. Isolation and culture of murine macrophages. Methods Mol Biol 2005; 290: 91-103.

Supplementary Information accompanies this paper on Cell Death and Differentiation website (http://www.nature.com/cdd) 